\title{
Profiling of Saharan dust and biomass-burning smoke with multiwavelength polarization Raman lidar at Cape Verde
}

\author{
By MATTHIAS TESCHE ${ }^{1,2, *}$, SILKE GROSS ${ }^{3,4}$, ALBERT ANSMANN ${ }^{1}$, DETLEF MÜLLER ${ }^{1,5}$, \\ DIETRICH ALTHAUSEN ${ }^{1}$, VOLKER FREUDENTHALER ${ }^{3}$ and MICHAEL ESSELBORN ${ }^{6}$ \\ ${ }^{1}$ Leibniz Institute for Tropospheric Research (IfT), Permoserstraße 15, 04318 Leipzig, Germany; ${ }^{2}$ Department of \\ Environmental Science (ITM), Stockholm University, Svante Arrhenius väg 8c, 10691 Stockholm, Sweden; \\ ${ }^{3}$ Meteorological Institute, Ludwig-Maximilians-Universität, Theresienstraße 37, 80333 Munich, Germany; ${ }^{4}$ Institute \\ for Atmospheric Physics, German Aerospace Center (DLR), Oberpfaffenhofen, 82234 Wessling, Germany; \\ ${ }^{5}$ Atmospheric Remote Sensing Laboratory, Gwangju Institute of Science and Technology, Gwangju 500-712, Republic \\ of Korea; ${ }^{6}$ European Southern Observatory (ESO), Karl-Schwarzschild-Straße 2, 85748 Garching, Germany
}

(Manuscript received 31 October 2010; in final form 3 May 2011)

\begin{abstract}
AB STRACT
Extensive lidar measurements of Saharan dust and biomass-burning smoke were performed with one airborne and three ground-based instruments in the framework of the second part of the SAharan Mineral dUst experiMent (SAMUM-2a) during January and February of 2008 at Cape Verde. Further lidar observations with one system only were conducted during May and June of 2008 (SAMUM-2b). The active measurements were supported by Sun photometer observations. During winter, layers of mineral dust from the Sahara and biomass-burning smoke from southern West Africa pass Cape Verde on their way to South America while pure dust layers cross the Atlantic on their way to the Caribbean during summer. The mean 500-nm aerosol optical thickness (AOT) observed during SAMUM-2a was 0.35 \pm 0.18 . SAMUM-2a observations showed transport of pure dust within the lowermost $1.5 \mathrm{~km}$ of the atmospheric column. In the height range from 1.5 to $5.0 \mathrm{~km}$, mixed dust/smoke layers with mean lidar ratios of $67 \pm 14 \mathrm{sr}$ at 355 and $532 \mathrm{~nm}$, respectively, prevailed. Within these layers, wavelength-independent linear particle depolarization ratios of 0.12-0.18 at 355,532 , and $710 \mathrm{~nm}$ indicate a large contribution (30-70\%) of mineral dust to the measured optical properties. Ångström exponents for backscatter and extinction of around 0.7 support this finding. Mean extinction coefficients in the height range between 2 and $4 \mathrm{~km}$ were $66 \pm 6 \mathrm{Mm}^{-1}$ at $355 \mathrm{~nm}$ and $48 \pm 5 \mathrm{Mm}^{-1}$ at $532 \mathrm{~nm}$. Comparisons with airborne high-spectral-resolution lidar observations show good agreement within the elevated layers. 3-5 km deep dust layers where observed during SAMUM-2b. These layers showed optical properties similar to the ones of SAMUM-1 in Morocco with a mean 500-nm AOT of $0.4 \pm 0.2$. Dust extinction coefficients were about $80 \pm 6 \mathrm{Mm}^{-1}$ at 355 and $532 \mathrm{~nm}$. Dust lidar ratios were $53 \pm 10 \mathrm{sr}$ at 355 and $532 \mathrm{~nm}$, respectively. Dust depolarization ratios showed an increase with wavelength from $0.31 \pm 0.10$ at $532 \mathrm{~nm}$ to $0.37 \pm 0.07$ at $710 \mathrm{~nm}$.
\end{abstract}

\section{Introduction}

Together with sea salt, mineral dust is the most abundant natural aerosol in the Earth's atmosphere. Airborne dust particles absorb and scatter incident sunlight. Due to their size they can also interact with long-wave terrestrial radiation and thus influence the Earth's radiative budget in very complex ways. The magnitude and sign of the dust radiative forcing strongly depends

\footnotetext{
* Corresponding author.

e-mail: matthias.tesche@itm.su.se

DOI: $10.1111 /$ j.1600-0889.2011.00548.x
}

on the optical properties and the spacial distribution of dust in the atmosphere as well as on the reflectance of the underlaying surface. The strongly irregular shape of mineral dust particles poses large difficulties to radiative transfer modelling (e.g. in reproducing results of remote sensing measurements) because classical Mie theory cannot be applied for these calculations (Mishchenko et al., 1997).

Once lifted over the Earth's deserts mineral dust can form several kilometre deep layers in which particles can be transported over thousands of kilometres (Goudie and Middleton, 2001; Liu et al., 2008b). Thus despite few distinct sources desert dust is distributed over the entire globe. From the Saharan desert, 
the largest source of mineral dust, aerosol particles can be transported on several paths: over the Mediterranean to central Europe (Ansmann et al., 2003; Müller et al., 2009), over the Balkans or the Middle East to eastern Europe (Papayannis et al., 2008), or over the Atlantic ocean to the Caribbean and South America (Prospero and Carlson, 1972; Kaufman et al., 2005; Liu et al., 2008a; Ansmann et al., 2009a; Ben-Ami et al., 2009, 2010; Schepanski et al., 2009; Huang et al., 2010). In the latter case, dust is transported by the westerlies within a warm, dry, and well-separated Saharan air layer (SAL, Prospero and Carlson, 1972, 1980). Aerosol transport in the outflow region of western Africa shows a strong seasonal dependence. During winter a band of strong biomass-burning activity stretches from the equator to about $15^{\circ} \mathrm{N}$. Depending on the season and the respective position of the intertropical convergence zone (ITCZ) dust is transported at different elevation. During winter, when the ITCZ retreats far south, dust is transported in a rather shallow layer near the surface. That dust layer is topped by biomass-burning aerosol from fires in equatorial Africa (Prospero and Carlson, 1972; Kalu, 1979; Haywood et al., 2008; Johnson et al., 2008a,b; Ben-Ami et al., 2009; Schepanski et al., 2009; Ben-Ami et al., 2010). During summer the ITCZ is shifted northward while the maximum of fire activity now occurs further south in Central Africa. Consequently, deep layers of pure mineral dust are transported westward over the Atlantic to the Caribbean.

Sokolik et al. (2001) recommended to arrange column closure experiments on mineral dust that focus on vertically resolved investigations of the chemical, microphysical, optical, and radiative properties of dust particles. Even though ten years passed since this recommendation, still only few data on mineral dust exist. Several case studies of dust outbreaks to established measurement sites in Europe, America, Korea, and Japan are reported (Mattis et al., 2002; Ansmann et al., 2003; Müller et al., 2003; Balis et al., 2004; Mona et al., 2006; Perez et al., 2006; Papayannis et al., 2008; Müller et al., 2009). Furthermore, large field experiments like the Puerto Rican Dust Experiment (PRIDE, Reid et al., 2003), the Saharan Dust Experiment (SHADE, Tanré et al., 2003), the Dust and Biomass Experiment (DABEX, Haywood et al., 2008), or the United Arab Emirates Unified Aerosol Experiment (UAE², Reid et al., 2008) were performed. However, no significant improvement on how to handle non-spherical particles seems to have been achieved from these observations because they only captured snapshots of the actual dust situation and cannot be used to generalize the effects associated with mineral dust. They were not designed to collect the data necessary to understand all the feedbacks of mineral dust, or the experiments simply were to far away from the source region and did not encounter pure dust conditions that are needed for a reliable aerosol characterization. Therefore, the first SAharan Mineral dUst experiMent (SAMUM-1, Heintzenberg, 2009) was conducted in southern Morocco in May and June 2006, to study the microphysical, chemical, optical, and radiative properties of mineral dust aerosol near the source region. These measurements constitute the first column closure experiment on mineral dust in the tradition of LACE98 (Ansmann et al., 2002) and ACE-2 (Russel and Heintzenberg, 2000). The main results of this experiment are published in a special issue of Tellus 61B in 2009.

An overview of the second SAMUM experiment (SAMUM2) at Cape Verde, the rationale behind the two-step approach, and a discussion of previous endeavours regarding the characterization of mineral dust particles is given by Ansmann et al. (2011). The main campaign of SAMUM-2 with the same participants and equipment that proved successful during SAMUM-1 in Morocco was performed at the airport of Praia, Cape Verde $\left(15.0^{\circ} \mathrm{N}, 23.5^{\circ} \mathrm{W}, 75 \mathrm{~m}\right.$ above sea level, asl) in January and February of 2008. During this time the aerosol layers over Cape Verde originate from the Saharan desert and a belt of strong biomass-burning activity south of the Sahel. Lidar measurements were performed with the three ground-based Raman lidars and the airborne high spectral resolution lidar (HSRL) that already participated in SAMUM-1 (Heintzenberg, 2009; Tesche et al., 2009a).

An additional summer campaign was performed in May and June of 2008. During this time the aerosol lidar, the wind lidar, the Sun photometer, and the sounding station of the Leibniz Institute for Tropospheric Research (IfT) in Leipzig, Germany, were available for profiling of aerosol properties and meteorological parameters at the Praia site. In addition, ground-based in situ particle sampling was performed by the Technical University of Darmstadt. During summer, the area of strong biomass-burning activity is shifted southward and only mineral dust from northern Africa is transported to the equatorial North Atlantic. Thus the results of the summer campaign of SAMUM-2 can be compared to the findings of SAMUM-1 in Morocco to investigate possible aging effects of the Saharan dust plume on its way over the Atlantic ocean.

Note that SAMUM-2 is the first field experiment that covers both modes of transport (i.e., winter and summer) of African aerosols over the Atlantic ocean. Previous studies only captured snapshots because they were limited to a rather short time period (Tanré et al., 2003; Haywood et al., 2008), only considered passive satellite remote sensing without the possibility of vertical profiling (Kaufman et al., 2005), or were not able to fully resolve the complex aerosol conditions over the eastern tropical Atlantic, especially during winter, i.e., smoke-dominated layers can often not be discriminated due to the bad signal-to-noise ratio (BenAmi et al., 2009).

Lidar measurements of pure Saharan dust in Morocco are presented and discussed by Ansmann et al. (2009b), Esselborn et al. (2009), Freudenthaler et al. (2009), Heese et al. (2009), and Tesche et al. (2009a). The indirect effect of mineral dust (i.e., the influence on ice formation) observed in Morocco and at Cape Verde is discussed by Ansmann et al. (2008) and Ansmann et al. (2009b), respectively. Apart from the papers in this Special 
Issue, SAMUM-2 lidar observations were used to investigate the long-range transport of Saharan dust to the Amazon basin (Ansmann et al., 2009a) and to evaluate the data retrieval algorithm of the Cloud-Aerosol Lidar with Orthogonal Polarization (CALIOP, Winker et al., 2009) aboard the Cloud-Aerosol Lidar and Infrared Pathfinder Satellite Observations (CALIPSO) satellite (Wandinger et al., 2010). Knippertz et al. (2011) present lidar observations in the meteorological overview of SAMUM-2. A detailed description of the findings from the SAMUM-2 lidar observations will be given in this paper and in Groß et al. (2011a,b) and Tesche et al. (2011).

We begin this contribution with a brief description of the applied instruments and necessary corrections. The observations are discussed in Sections 3 and 4 for the winter and summer campaigns, respectively. In the respective sections case studies are presented before the observations are summarized in terms of the general findings. In the discussion in Section 5, summer versus winter conditions and SAMUM-1 versus SAMUM-2 are contrasted. We finish this contribution with a summary and an outlook in Section 6.

\section{Instrumentation}

The basic instrumental setup of SAMUM-1 (Heintzenberg, 2009) for ground-based and airborne in situ particle sampling and lidar observations as well as radiation measurements and soundings was deployed at the airport of Praia, Cape Verde. The DLR Falcon research aircraft participated in SAMUM-2 in order to perform regional observations of dust and biomassburning smoke in the Cape Verde region. This section gives a brief overview of the remote sensing instruments that were applied during SAMUM-2.

\subsection{Lidar}

The lidar setup of SAMUM-2 consisted of the MUltiwavelength LIdar System (MULIS, Freudenthaler et al., 2009) and the POrtable LIdar System (POLIS, Heese et al., 2009) of the Meteorological Institute (MIM) of the University of Munich, Germany, and the Backscatter Extinction lidar-Ratio Temperature Humidity Apparatus (BERTHA, Althausen et al., 2000; Tesche et al., 2009a) of IfT Leipzig. Additional airborne lidar measurements were performed with the High Spectral Resolution Lidar (HSRL, Esselborn et al., 2008) of the German Aerospace Center (DLR), Oberpfaffenhofen, Germany. These systems were described in detail by Freudenthaler et al. (2009), Tesche et al. (2009a), and Esselborn et al. (2008), respectively. After SAMUM-1, a halfwave plate was placed in front of the polarizing beamsplitter cube that separates the parallel and perpendicularly polarized light in the receiver of BERTHA. This modification allows for measurements of the linear volume depolarization ratio according to the method of Freudenthaler et al. (2009). The pool of three ground-based depolarization Raman lidars was extended
Table 1. Overview of the wavelengths (in $\mathrm{nm}$ ) at which the different lidar systems operated during SAMUM-2 can measure backscatter coefficients $\beta$, extinction coefficients $\sigma$, lidar ratios $S$, and depolarization ratios $\delta$.

\begin{tabular}{lllll}
\hline Lidar & \multicolumn{1}{c}{$\beta$} & \multicolumn{1}{c}{$\sigma$} & \multicolumn{1}{c}{$S$} & \multicolumn{1}{c}{$\delta$} \\
\hline BERTHA & $355,400,532$, & 355,532 & 355,532 & 710 \\
& $710,800,1064$ & & & \\
HSRL & 532,1064 & 532 & 532 & 532,1064 \\
MULIS & 355,532 & 355,532 & 355,532 & 532 \\
POLIS & 355 & 355 & 355 & 355 \\
\hline
\end{tabular}

with a Doppler wind lidar (Engelmann et al., 2011) for the measurement of the 3-D wind field over the measurement site.

All aerosol lidars employed during SAMUM-2 measure backscatter and extinction coefficients independently by applying the Raman or HSRL technique (Ansmann and Müller, 2005; Eloranta, 2005). Thus they directly measure the extinction-tobackscatter (lidar) ratio, which is a key parameter for aerosol characterization (Müller et al., 2007). Measurements of the lidar ratio were performed at $355 \mathrm{~nm}$ (POLIS, MULIS, and BERTHA) and $532 \mathrm{~nm}$ (MULIS, HSRL, and BERTHA). Furthermore, all systems are equipped with polarization channels in order to obtain profiles of the linear particle depolarization ratio (Sassen, 2005). These measurements are performed at $355 \mathrm{~nm}$ (POLIS), $532 \mathrm{~nm}$ (MULIS, HSRL), and $710 \mathrm{~nm}$ (BERTHA). A summary of the measurement capabilities of the lidars applied during SAMUM-2 is given in Table 1.

As described in Mattis et al. (2009) and Tesche et al. (2009a), the 532-nm elastic backscatter channel of the receiver of BERTHA is affected by polarization-dependent receiver transmission. Backscattered signals at different states of polarization are detected with different efficiencies, which results in an under- or overestimation of the total signal. The effect could not be solved between the two SAMUM campaigns and needs to be accounted for, when highly depolarizing scatterers like mineral dust or ice crystals are present in the atmosphere (i.e., during all SAMUM-2 measurements). Thus a correction is necessary to obtain reliable 532-nm backscatter coefficients and lidar ratios (Tesche et al., 2009a). For this, profiles of the 532-nm volume depolarization ratio need to be known. During the winter campaign, these were provided by MULIS measurements. During summer only BERTHA remained for measurements at the airport of Praia. Therefore, a formalism to estimate 532-nm volume depolarization ratios from the BERTHA measurements at $710 \mathrm{~nm}$ was required to correct the measurements of the 532-nm backscatter channel. During the winter campaign, we performed coincident measurements with BERTHA and MULIS during $12 \mathrm{~d}$. The obtained profiles of the linear volume depolarization ratio $\delta_{\lambda}^{v}$ at 532 and $710 \mathrm{~nm}$ were correlated as shown in Fig. 1. Based on 537 data points (height levels) we found the following linear relationship between the volume depolarization ratios at 


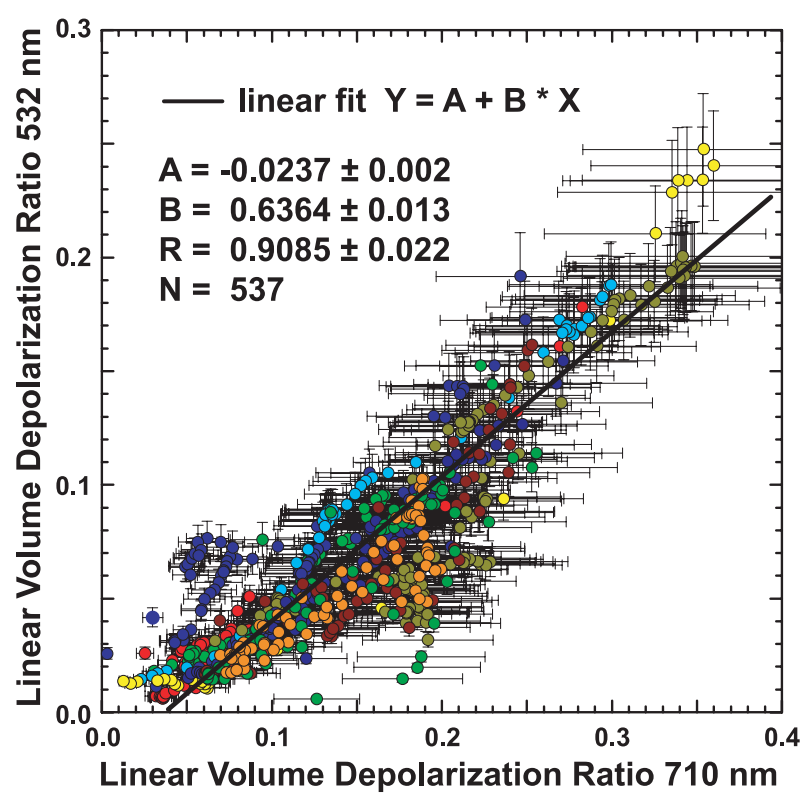

Fig. 1. Correlation of linear volume depolarization ratios as measured with BERTHA at $710 \mathrm{~nm}$ ( $20 \%$ error bar) and with MULIS at $532 \mathrm{~nm}$ (10\% error bar). Different colours denote correlative measurements during $12 \mathrm{~d}$ of SAMUM-2a. The black line represents the linear relation used to transform BERTHA volume depolarization ratios to $532 \mathrm{~nm}$.

\section{2 and $710 \mathrm{~nm}$}

$\delta_{532}^{\mathrm{v}}=-0.0237+0.6364 \delta_{710}^{\mathrm{v}}$.

As is visible for the dots of different colour (different days) in Fig. 1, a linear fit might not initially seem to be the best choice for individual cases. To assure the reliability of the regression, we performed linear and polynomial fits for each of the 12 comparison days. Both fits generally showed equally high correlations of $0.85-0.99$. The linear fit was found to be very stable while the coefficients of the polynomial fit showed a large variability (including a change in curvature). To test for the applicability of the extrapolation method, the retrieved 532-nm depolarization-ratio profiles were compared to the ones measured with MULIS. They were also used for the correction of depolarization-dependent receiver transmission. The low variability of the fit coefficients facilitates that the linear fit of one comparison day led to good results for the next day. In contrast to that, the polynomial fit of one day led to highly biased results for the next day. Generally, we found the maximum error between extrapolated and measured 532-nm volume depolarization-ratio profile to be between 20 and $30 \%$, if the mean linear fit is applied to slightly smoothed (60-m window length) profiles. The deviation decreases, if longer smoothing lengths are used (as is the case in this study).

The correction of polarization-dependent receiver transmission for a winter (31 January 2008) and a summer (3 June 2008) measurement is presented in Figs 2 and 3, respectively. The fig- ures are analogous with Fig. 3 of Tesche et al. (2009a). The dotted line in Fig. 2a denotes the uncorrected 532-nm backscatter profile. A large deviation to the unaffected MULIS measurements (thin line) can be observed, especially in the lowermost $1.5 \mathrm{~km}$ that were dominated by mineral dust. The use of the 532-nm volume depolarization ratio (bold line in b) estimated from the measurement at $710 \mathrm{~nm}$ (dotted line in b) leads to a correction factor (bold line in c) similar to the one retrieved with the measured MULIS volume depolarization ratio profile (thin line in c). Almost no difference can be recognized in the corrected 532-nm backscatter profile, when the two correction functions (shown in c) are used. Thus the application of the MULIS-derived correction function (thin line in c) is not shown in Fig. 2a.

Figure 3 shows the application of the correction of polarization-dependent receiver transmission for a measurement during the SAMUM-2 summer campaign in 2008. Now, the results cannot be verified with MULIS measurements, because measurements were performed only with BERTHA. However, BERTHA's rotational-Raman channels (three additional measurement channels for the measurements of light from elastic and pure rotational-Raman scattering at $532 \mathrm{~nm}$, Althausen et al., 2000; Arshinov et al., 2005) were operational during SAMUM-2b. These channels incorporate an additional 532-nm elastic backscatter channel that is not affected by polarizationdependent receiver transmission (Tesche et al., 2009a). Thus they can be used to validate the correction of the 532-nm backscatter profile. The uncorrected profile and the 710-nm volume depolarization ratio are shown as dotted lines in Figs $3 a$ and b, respectively. The transformation of the volume depolarization ratio according to eq. (1) leads to the bold line in Fig. 3b. The thin line in Fig. $3 \mathrm{~b}$ represents a depolarization ratio profile that is obtained by adjusting an artificial correction function in a way to exactly reproduce the measurement of the rotational-Raman channels. Thus an independent method for the verification of the correction of the 532-nm elastic backscatter signal is given. The application of the correction function calculated from the transformed volume depolarization ratio results in a 532-nm backscatter profile (bold line in a) that is in good agreement with the independently obtained results of the rotational-Raman channels (thin line in a). Due to their large height of complete overlap of 2.5$3.0 \mathrm{~km}$ from the lidar, the rotational-Raman channels could not be used for a general analysis of 532-nm backscatter and extinction coefficients.

For the analysis (Klett's method during daytime, Raman method during nighttime, see Ansmann and Müller, 2005) 30-270 min of cloud-screened lidar measurements were averaged. To further reduce signal noise, the averaged profiles were smoothed vertically with windows of $80-660 \mathrm{~m}$. The length of the smoothing window usually was increased with height. For BERTHA measurements, the error of the particle backscatter coefficients at 355 and $1064 \mathrm{~nm}$ is in the range of 5\%. Due to the correction of the depolarization-dependent receiver transmission of the $532 \mathrm{~nm}$ elastic backscatter channel, 532-nm particle 

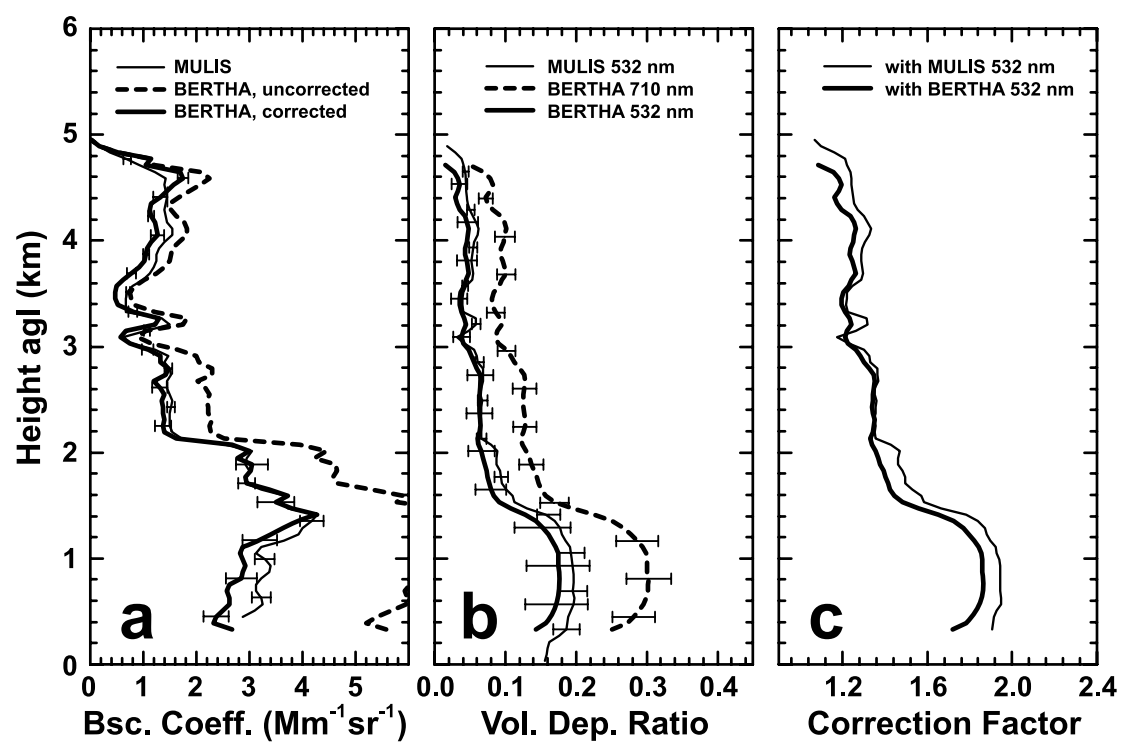

Fig. 2. Correction of the effect of polarization-dependent receiver transmission on the measured backscatter coefficients (a) for the evening measurement of 31 January 2008. 532-nm linear volume depolarization ratios measured with MULIS (thin line in b) and transformed to $532 \mathrm{~nm}$ (bold line in b) from the 710-nm BERTHA measurement (dashed line in b) were used to obtain the respective correction functions (c). The application of the correction functions allows for the calculation of a corrected 532-nm backscatter profile (bold line in a) that is in agreement with the unaffected MULIS measurement (thin line in a). The different functions in (c) yield no recognizable difference in the corrected profile (bold line in a). Thus the transformed BERTHA volume depolarization ratio profile is appropriate for the correction of polarization dependent receiver transmission.
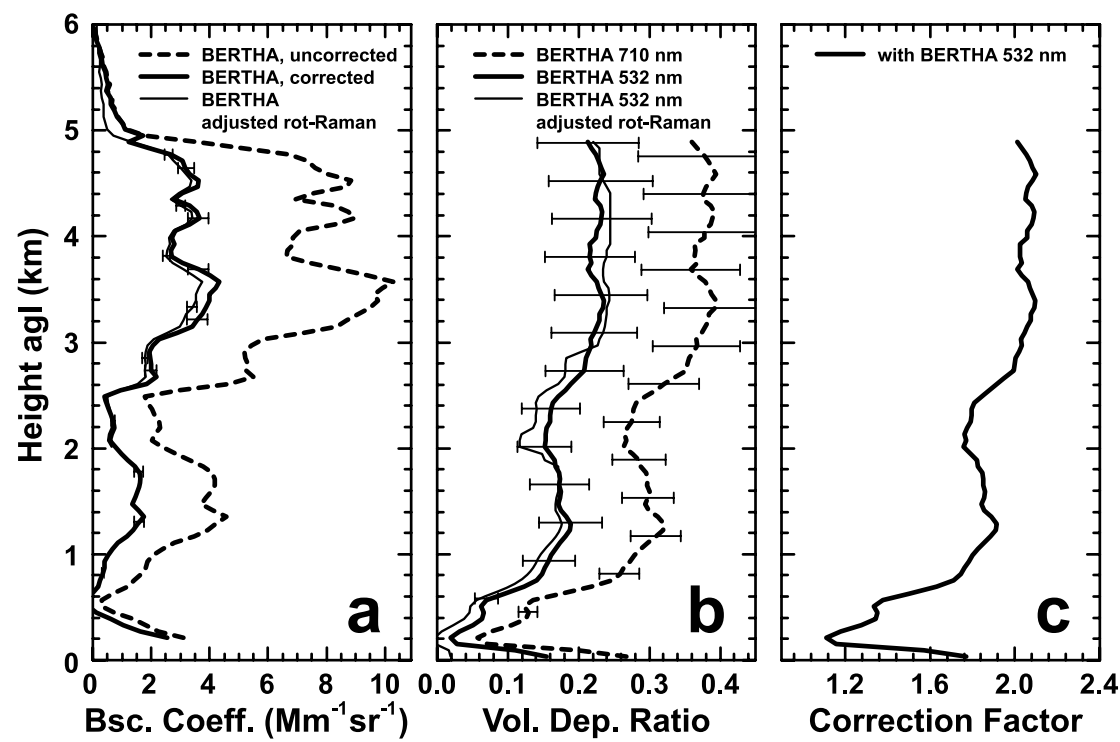

Fig. 3. Same as Fig. 2 but for an evening measurement on 3 June 2008. No MULIS measurements were available during the summer campaign. The corrected profiles are therefore compared to the results of the rotational-Raman channels (thin line in a) that are not affected by polarizationdependent receiver transmission. The thin line in (b) is an artificial depolarization ratio profile that was adjusted until an agreement with the unaffected rotational-Raman channels was obtained.

backscatter coefficients are assumed to have an error of about $10 \%$. The error of the particle extinction profiles derived from the nitrogen Raman signal is in the range of $15-25 \%$. The errors of the lidar ratios and the Ångström exponents are calculated according to Gaussian error propagation. The error of the lidar ratio is estimated to be in the range of $25-45 \%$. The error of the Ångström exponents strongly depends on the input parameters. It can be as high as $100 \%$. Depolarization measurements with BERTHA were improved before SAMUM-2. The error of the volume depolarization ratio at $710 \mathrm{~nm}$ could be reduced to 
$10-15 \%$. Consequently, the particle depolarization ratio could be obtained with an error of $15-20 \%$. Thus the respective results of SAMUM-2 are much more reliable than the ones for the measurements in Morocco. The 532-nm depolarization ratios retrieved from the BERTHA measurements at $710 \mathrm{~nm}$ according to eq. (1) have an error that increased by about 10 percentage points compared to the respective measurement at $710 \mathrm{~nm}$.

As described in Tesche et al. (2009a), the overlap function of the laser-beam with the receiver field-of-view for BERTHA is derived according to the method proposed by Wandinger and Ansmann (2002). BERTHA particle backscatter profiles derived with the Raman method (Ansmann and Müller, 2005) are trustworthy down to several hundred metres above ground level. The remaining distance to the surface is covered by the smaller systems of Munich University. Due to the overlap effect BERTHA particle extinction profiles are trustworthy only above $1.5-2.0 \mathrm{~km}$ height from the lidar. Thus extinction coefficients and lidar ratios at lower heights were retrieved with POLIS and MULIS (Groß et al., 2011a,b) as will be shown in the next paragraph.

To fully exploit the measurements of the three ground-based systems the collected information is shown in Fig. 4 for the evening measurement of 31 January 2008. This case is discussed in detail by Tesche et al. (2009b). MULIS and POLIS cover the overlap range of BERTHA and together the three instruments deliver measurements of the particle depolarization ratio at three different wavelengths. Furthermore, the quality of the results of the different lidar systems is assured. BERTHA backscatter coefficients (unsmoothed below $2.4 \mathrm{~km}$ height, 300$\mathrm{m}$ smooth above) at $355 \mathrm{~nm}$ (dark blue), $532 \mathrm{~nm}$ (dark green), and $1064 \mathrm{~nm}$ (red) are combined with MULIS 532-nm profiles (light green, 82.5-m smooth, until $2 \mathrm{~km}$ height) and POLIS 355$\mathrm{nm}$ profiles (light blue, $82.5-\mathrm{m}$ smooth, until $2 \mathrm{~km}$ height). The combination was performed in a height range $(1.4-2.0 \mathrm{~km})$ in which reliable results were found for all lidar systems. The extinction profiles were derived in the same manner. BERTHA profiles at $355 \mathrm{~nm}$ (dark blue, $2.0-6.0 \mathrm{~km}$ height) and $532 \mathrm{~nm}$ (dark green, 1.2-6.0 km height) are smoothed with a window length of $300 \mathrm{~m}$. Measurements with POLIS (355 nm, light blue, $0.2-2.4 \mathrm{~km}$ height) and MULIS (532 nm, light green, 0.6-1.2 $\mathrm{km}$ height) are smoothed with a window length of $82.5 \mathrm{~m}$. Lidar ratios and Ångström exponents (not shown) were then calculated from the combined backscatter and extinction profiles. The linear particle depolarization ratio profiles were obtained with POLIS (355 nm, light blue), MULIS (532 nm, light green), and BERTHA (710 nm, magenta) according to the method of Freudenthaler et al. (2009). The respective particle depolarization ratios were calculated from the volume depolarization ratio $\delta_{\lambda}^{\mathrm{v}}$, the particle backscatter coefficient $\beta_{\lambda}^{\mathrm{p}}$, the molecular backscatter coefficient $\beta_{\lambda}^{\mathrm{m}}$, and the molecular (Rayleigh) depolarization ratio $\delta_{\lambda}^{\mathrm{m}}$ as

$$
\delta_{\lambda}^{\mathrm{p}}=\frac{\beta_{\lambda}^{\mathrm{m}}\left(\delta_{\lambda}^{\mathrm{v}}-\delta_{\lambda}^{\mathrm{m}}\right)+\beta_{\lambda}^{\mathrm{p}} \delta_{\lambda}^{\mathrm{v}}\left(1+\delta_{\lambda}^{\mathrm{m}}\right)}{\beta_{\lambda}^{\mathrm{m}}\left(\delta_{\lambda}^{\mathrm{m}}-\delta_{\lambda}^{\mathrm{v}}\right)+\beta_{\lambda}^{\mathrm{p}}\left(1+\delta_{\lambda}^{\mathrm{m}}\right)} .
$$
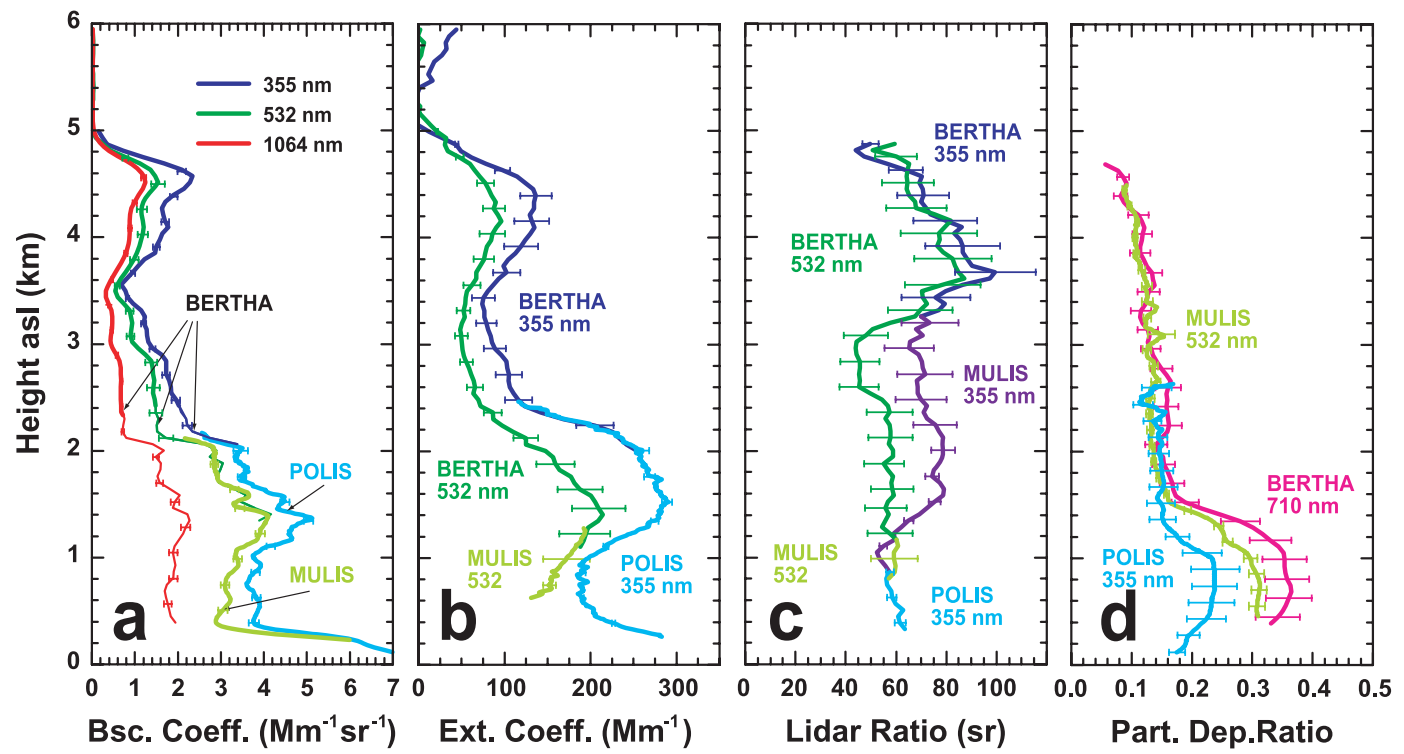

Fig. 4. Evening measurement of 31 January 2008. Backscatter coefficients (a), extinction coefficients (b), lidar ratios (c), and linear depolarization ratios (d) are shown as combined profiles measured with BERTHA (2132-2232 UTC; 355, 532, and 1064 nm; dark profiles), MULIS (2015-2215 UTC; $532 \mathrm{~nm}$; light green), and POLIS (2015-2215 UTC; $355 \mathrm{~nm}$; light blue). In case of the backscatter coefficients thin dark lines denote unsmoothed BERTHA measurements while thick dark lines represent measurements smoothed with a window length of $300 \mathrm{~m}$. Measurements with POLIS and MULIS are smoothed with a window length of $82.5 \mathrm{~m}$. The smoothing lengths of the other profiles are given in the text. Error bars consider uncertainties in the retrieved input parameters and signal noise. 
The molecular backscatter coefficient can be calculated from radiosonde data or a model atmosphere according to Bucholtz (1995). The molecular depolarization ratio is a constant factor that depends on the bandwidth of the interference filters in the lidar receiver. Because the volume depolarization ratio still includes the molecular information (with a larger contribution of molecules at lower wavelengths), a spectral variation of this parameter not necessarily needs to show up in the inferred particle depolarization ratio. For common aerosol loads, the difference between volume and particle depolarization ratio decreases with wavelength. For a single wavelength, the difference between volume and particle depolarization ratio decreases with increasing particle backscatter coefficient.

The profiles of the particle depolarization ratio are only slightly smoothed with vertical windows of $82.5 \mathrm{~m}$ (MULIS and POLIS) and $150 \mathrm{~m}$ (BERTHA). They show that pure dust is present in the lowermost kilometre of the atmospheric column. The values of 0.3 at $532 \mathrm{~nm}$ are in good agreement with the dust depolarization ratio of $0.31 \pm 0.03$ observed during SAMUM-1 (Freudenthaler et al., 2009). Furthermore, an increase of the particle depolarization ratio with wavelength is found. This effect was reproduced in the modelling study by Gasteiger et al. (2011). Similarly high dust depolarization ratios (showing the same wavelength dependence) were observed during the summer measurements of SAMUM-2 (see Section 4). As is discussed in detail by Groß et al. (2011a), no wavelength dependence of the particle depolarization ratios is found in the mixed dust/smoke layer were values vary between 0.12 and 0.16 .

Lidar measurements during SAMUM-2 were performed during noon and after sunset and accompanied by radiosonde ascents. Additional measurements were conducted, when the CALIPSO satellite passed the ground site at a distance of less than $500 \mathrm{~km}$. These observations were used to evaluate CALIPSO measurements using established polarization Raman lidars (Wandinger et al., 2010). Such comparisons are of great value for quality assurance of the space-borne instrument and its retrieval algorithm which selects lidar ratios for different aerosol types according to a look-up table (Omar et al., 2009) — especially in the dusty environment of the tropical North Atlantic.

\subsection{Sun photometry}

Three Sun photometers performed measurements: the Sun-Sky Automatic RAdiometer (SSARA) of the Meteorological Institute of the University of Munich (Toledano et al., 2009, 2011), a portable version of the AErosol RObotic NETworks (AERONET, Holben et al., 1998, http://aeronet.gsfc.nasa.gov/) Cimel instrument, and a SP1A manufactured by Dr. Schulz and Partner, Buckow, Germany. The latter was the only instrument available for the summer measurements. All Sun photometers measured aerosol optical thickness (AOT) at several wavelength in the range $340-1020 \mathrm{~nm}$. SSARA and the AERONET instru- ment even covered larger wavelength of up to $1550 \mathrm{~nm}$. SSARA furthermore performed almucantar measurements of sky brightness (Toledano et al., 2011).

The Sun photometer measurements of AOT at $500 \mathrm{~nm}$ and Ångström exponents (Ångström, 1964) for the wavelengths pair $440 / 870 \mathrm{~nm}$ during SAMUM-2a presented in this paper were obtained with SSARA (15 January to 9 February 2008, Toledano et al., 2011) and the AERONET instrument (10-14 February 2008). Good agreement was found between the two instruments in the time range of coincident measurements between 23 January and 9 February 2008.

\subsection{Radiosondes}

Along with the lidar measurements, modern radiosondes of type Vaisala RS92 (which measure temperature, air pressure, relative humidity, and wind speed and direction) were launched during noon (1100-1200 UTC) while older Vaisala RS80 (which measure temperature, air pressure, and relative humidity) were launched in the evening (2000-2100 UTC). Additional radiosondes were launched during Falcon overflights, CALIPSO overpasses, and very long measurements. A total number of 33 RS92 and 29 RS80 was launched during the one-month measurement period in winter of 2008 . We proceeded accordingly during the summer campaign and launched 20 RS92 and 15 RS80.

\section{SAMUM-2a Observations}

The winter campaign of SAMUM-2 was performed from 15 January to 14 February 2008. A meteorological overview of this time period is given by Knippertz et al. (2011). In this section we present two case studies of 22 January 2008 and 6 February 2008 which are representative for the different aerosol conditions encountered during the winter campaign (Knippertz et al., 2011). Further cases and a deeper analysis of the lidar measurements with respect to particle microphysical properties are discussed in Tesche et al. (2009b, 2011).

Figure 5 gives a regional view of the aerosol conditions over western Africa during winter. The left panel shows active fires on the African continent in the period from 31 January to 9 February 2008 as provided by the MODIS rapid response system (http://rapidfire.sci.gsfc.nasa.gov/firemaps/). It is typical for the winter season that southern West Africa is covered by a belt of strong fire activity between 5 and $15^{\circ} \mathrm{N}$. The southerly position of the ITCZ (indicated as a green band) allows westward transport of the biomass-burning smoke which accumulates over the Gulf of Guinea to the Cape Verde islands (red circle). The right panel is a map of MODIS mean AOT at $550 \mathrm{~nm}$ for the four-week period of the SAMUM-2 winter observations. The map was compiled using the GES-DISC (Goddard Earth Sciences Data and Information Services Center) Interactive Online Visualization ANd aNalysis Infrastructure (Giovanni, Acker and Leptoukh, 

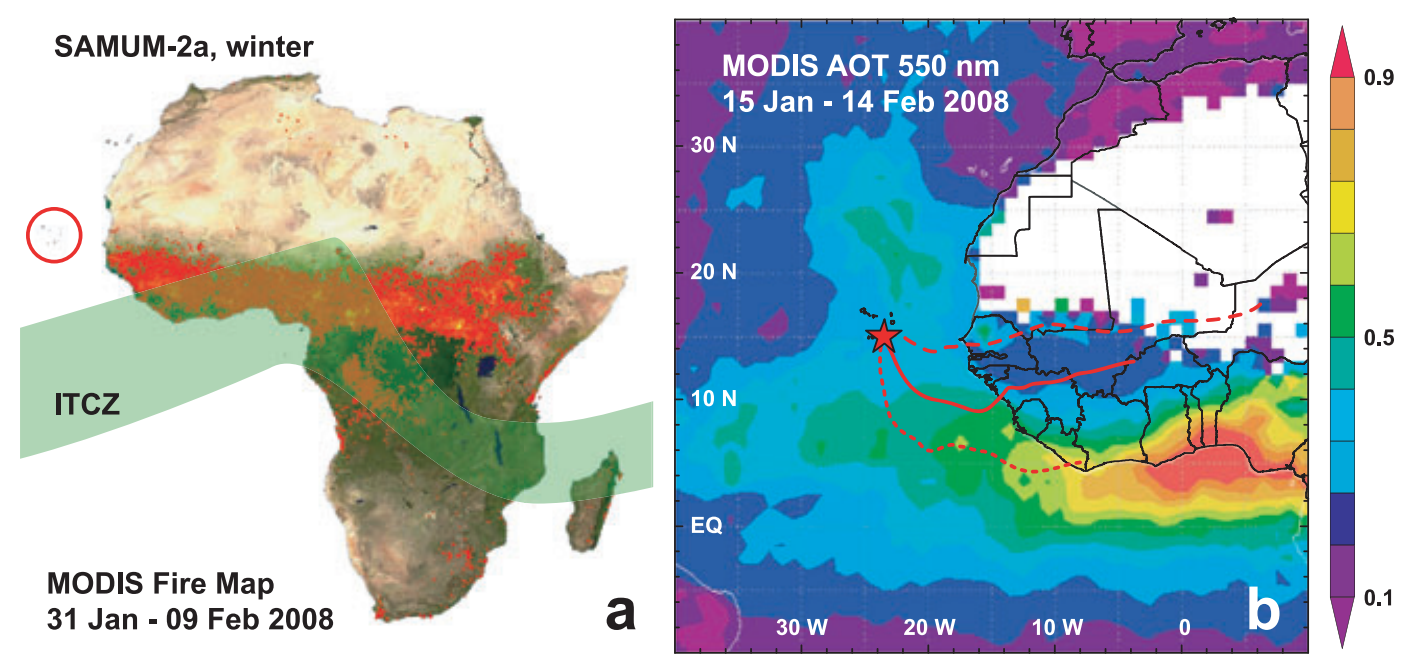

Fig. 5. (a) Position of the ITCZ during winter (green area) underlaid with MODIS maps of active fires in $10 \mathrm{~d}$ example periods during SAMUM-2a. The red circle in the left picture marks the location of Cape Verde west of the African continent. (b) MODIS mean optical depth at $550 \mathrm{~nm}$ for the four-week period of the SAMUM-2 winter campaign. The red lines denote examples of $72 \mathrm{~h}$-backward trajectories that arrive within the observed aerosol layer at $500 \mathrm{~m}$ (dashed), $2500 \mathrm{~m}$ (solid), and $4500 \mathrm{~m}$ (short dashed) above ground level. MODIS fire maps are taken from the archive accessible at http://rapidfire.sci.gsfc.nasa.gov/firemaps/. The adjusted colour plots of MODIS 550-nm optical depth are compiled using Giovanni (http://daac.gsfc.nasa.gov/giovanni/).

2007, http://daac.gsfc.nasa.gov/giovanni/). High AOT prevails in the biomass-burning region. The aerosol plume extends over the tropical north Atlantic to a longitude of $40^{\circ} \mathrm{W}$. Further to the north, a second plume is visible between 15 and $30^{\circ} \mathrm{N}$ that might be attributed to Saharan dust plumes (see Fig. 7d in Knippertz et al., 2011). Three-day HYSPLIT (Draxler and Rolph, 2010, http://ready.arl.noaa.gov/HYSPLIT.php) backward trajectories arriving over Praia at 2100 UTC on 31 January 2008 (details described in the figure caption) show that air at levels below 1 $\mathrm{km}$ height is advected from the desert areas of northern Africa and does not pass the region of biomass-burning activity (see also Fig. 2 in Tesche et al., 2009b). Air at greater heights originates from central Africa or at least passes the region of active fires. The trajectories are shown as a general example for the prevailing air flow and they are in agreement with the detailed trajectory analysis presented by Knippertz et al. (2011).

Figure 1 of Knippertz et al. (2011) gives an overview of the SAMUM-2 measurement period in terms of the vertical extent of aerosol (maritime, dust, dust+smoke) layers, the 500-nm AOT and 440/870-nm Ångström exponents as well as mass concentrations measured at ground level. A detailed discussion of the Sun photometer measurements during SAMUM-2 is provided by Toledano et al. (2011). The measurements of particle mass concentrations are presented by Kandler et al. (2011). The respective papers also discuss the uncertainty of the measurements. We usually observed a maritime boundary layer (with depolarization ratios close to zero) that made up the lowermost $0.4-1.0 \mathrm{~km}$ of the atmospheric column. During most days, a mineral dust layer was present over the maritime boundary layer (or even from the surface in cases of strong dust outbreaks) to a height of $1.5 \mathrm{~km}$ asl. Mineral dust layers can easily be detected by means of depolarization lidar because these large non-spherical particles cause high values of the linear particle depolarization ratio ( $>0.3$, Freudenthaler et al., 2009). Above the mineral dust layer, we observed a mixed layer of mineral dust from North Africa and biomass-burning smoke from southern West Africa during most of the time. Biomass-burning particles cause low depolarization ratios of around 0.05 (Tesche et al., 2009 b). A detailed study of the aerosol types and mixing states based on depolarization-ratio measurements is given by Groß et al. (2011a,b) and Tesche et al. (2011).

\subsection{Case studies}

Evening measurements on 22 January 2008 and 6 February 2008 are selected to study the varying conditions that were encountered during the winter measurements of SAMUM-2 (Ansmann et al., 2011; Knippertz et al., 2011). The case studies are discussed in terms of lidar and Sun photometer measurements, radiosonde profiles, and backward trajectories.

3.1.1. 22 January 2008. 22 January 2008 was one of the first cloudless SAMUM-2 measurement days. The Falcon aircraft performed its first research flight (Weinzierl et al., 2011). Continuous lidar and Sun photometer measurements from 1200 to 2200 UTC on 22 January 2008 are presented in Fig. 6 together with profiles of meteorological parameters obtained from the radiosonde launched at 1410 UTC. The time series of 500-nm optical depth (green dots) and 440/870-nm Ångström exponents (white dots) in Fig. 6a indicates rather homogeneous conditions throughout the day. Good agreement is found between daytime 


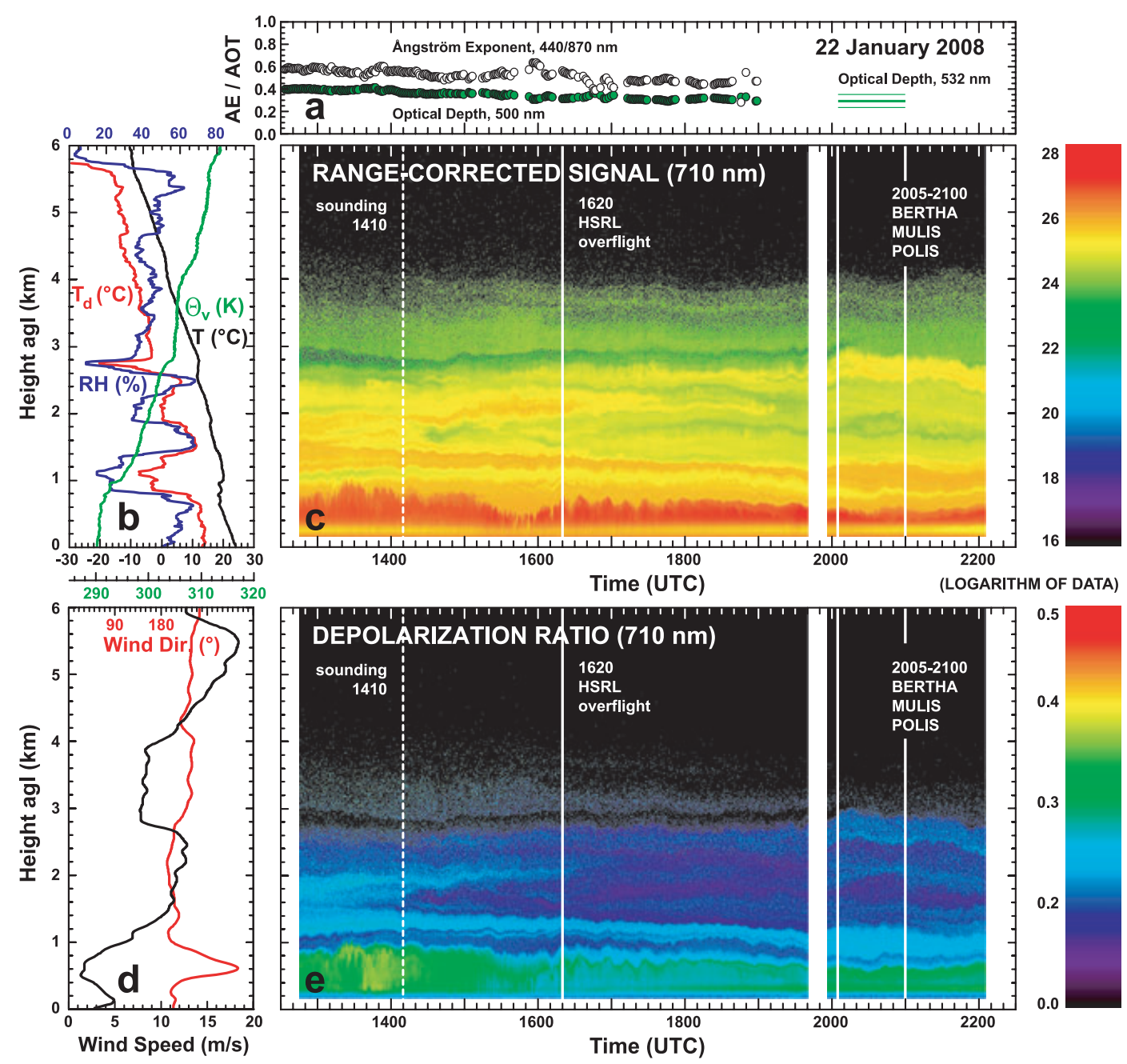

Fig. 6. Observations of 1245-2205 UTC on 22 January 2008. Sun photometer measurements (a) of optical depth (green dots) at $500 \mathrm{~nm}$ and the 440/870-nm Ångström exponent (white dots) are shown together with the evolution of the aerosol layer in terms of (c) the range-corrected signal and (e) the linear volume depolarization ratio. Meteorological profiles of the radiosonde launched at 1410 UTC (dotted line in c and e) are shown in (b) and (d). The Falcon research aircraft (equipped with the HSRL) passed the measurement site at 1620 UTC (left white line). The nighttime measurement was performed from 1958 to 2205 UTC (after the gap in c and e). Coincident measurements with BERTHA, MULIS, and POLIS were performed from 2005 to 2100 UTC (between the solid white lines in c and e). The respective profiles are shown in Figs 7 and 8 . The 532-nm optical depth of this measurement is shown as a bold horizontal line in (a). Thin green lines mark the range of possible values, if a maximum uncertainty of $20 \%$ is considered in the integration of the lidar-derived extinction profile.

Sun photometer optical depths at $500 \mathrm{~nm}(0.40$, decreasing to 0.31 ) and the value of 0.29 retrieved by integration of the lidar extinction measurements at $532 \mathrm{~nm}$ after sunset (bold horizontal green line). Column Ångström exponents of 0.6-0.4 indicate a significant influence of large mineral dust particles that decrease the otherwise high value for biomass-burning smoke of $>1$ (Eck et al., 1999).

The time-height display of the 710-nm range-corrected signal in Fig. 6c (as a measure of the strength of the returned signal) and the profiles of temperature and relative humidity in Fig. $6 \mathrm{~b}$ show several aerosol layers up to a height of $4 \mathrm{~km}$. In the depolarization plot in Fig. 6e, the aerosol layer can only by recognized up to $3 \mathrm{~km}$ height due to the low aerosol concentration above. A strong decrease of the depolarization ratio is visible between 0.8 and $1.0 \mathrm{~km}$ height. In the lowermost kilometre mineral dust from northern Africa dominates. This also produces the low Ångström exponents in Fig. 6a. The layers above $1 \mathrm{~km}$ height are composed of a mixture of mineral dust and biomass-burning smoke from southern West Africa. Due to the non-negligible contribution of dust, the elevated layers are referred to as smoke-dominated layers or (mixed) dust/smoke layers instead of smoke layers (Tesche et al., 2009b, 2011; Knippertz et al., 2011). The results of the airborne in situ measurements performed on 22 January 2008 are discussed in Lieke et al. (2011) and Weinzierl et al. (2011). 

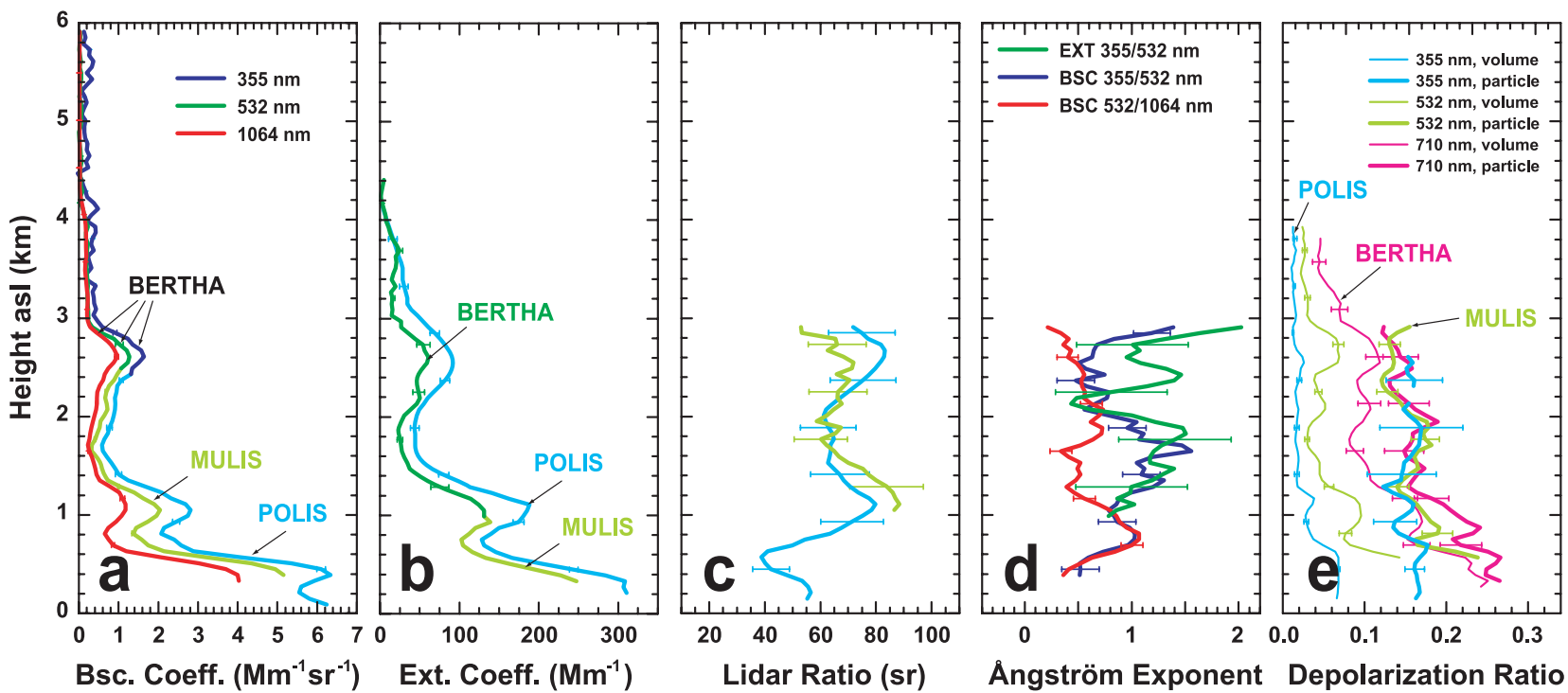

Fig. 7. Evening measurement of 22 January 2008. Backscatter (a) and extinction coefficients (b), lidar ratios (c), Ångström exponents (d), and linear depolarization ratios (e) are shown as combined profiles measured with BERTHA (2005-2100 UTC; 355, 532, and 1064 nm; dark green, red, and blue profiles), MULIS (2005-2100 UTC; $532 \mathrm{~nm}$; light green), and POLIS (2005-2100 UTC; $355 \mathrm{~nm}$; light blue). Lidar ratios and backscatter- and extinction-related Ångström exponents (marked as BSC and EXT, respectively) are calculated from the combined profiles shown in (a) and (b). The smoothing lengths of the different profiles are given in the text.

A 1-h period (from 2005 to 2100 UTC, indicated by two white lines in Figs $6 \mathrm{c}$ and e) of the evening measurement during which all three ground-based systems measured simultaneously was chosen to compile combined profiles of backscatter and extinction coefficients, lidar ratios, Ångström exponents, and linear volume and particle depolarization ratios. The results are shown in Fig. 7. Because POLIS cannot perform Raman and depolarization measurements simultaneously, the 355-nm depolarization ratios shown in Fig. 7e were computed from measurements from 1830 to 1930 UTC. As in Fig. 4, the different colours of the profiles refer to the different lidar systems: POLIS (355 nm, light blue), MULIS (532 nm, light green), and BERTHA (355 $\mathrm{nm}$, dark blue; $532 \mathrm{~nm}$, dark green; $1064 \mathrm{~nm}$, red; and $710 \mathrm{~nm}$, magenta).

Particle backscatter coefficients measured with BERTHA are unsmoothed below a height of $1.8 \mathrm{~km}$. Above they are smoothed with a vertical window of $300 \mathrm{~m}$ that was also used to smooth the 532-nm extinction coefficient. The POLIS 355-nm backscatter coefficient (light blue, below $2730 \mathrm{~m}$ height) is smoothed with vertical windows of 82.5 and $157.5 \mathrm{~m}$ below and above $1.34 \mathrm{~km}$ height, respectively. The corresponding extinction coefficient is smoothed with windows of $157.5 \mathrm{~m}$ below $507 \mathrm{~m}$ height, $397.5 \mathrm{~m}$ between 507 and $1250 \mathrm{~m}$ height, and $652.5 \mathrm{~m}$ above $1250 \mathrm{~m}$ height. MULIS backscatter coefficients (light green, below $2550 \mathrm{~m}$ height) and extinction coefficients below $2 \mathrm{~km}$ height are smoothed with $82.5 \mathrm{~m}$ window length. The error bars are similar to the ones explained for Fig. 4.

In the profiles of backscatter and extinction distinct peaks can be recognized in the planetary boundary layer at about 0.5 $\mathrm{km}$ height $\left(6 \mathrm{Mm}^{-1} \mathrm{sr}^{-1}\right.$ and $300 \mathrm{Mm}^{-1}$ at $\left.355 \mathrm{~nm}\right)$ and in elevated layers at $1.0 \mathrm{~km}$ height $\left(3 \mathrm{Mm}^{-1} \mathrm{sr}^{-1}\right.$ and $200 \mathrm{Mm}^{-1}$ at $355 \mathrm{~nm})$ and at $2.5 \mathrm{~km}$ height $\left(2 \mathrm{Mm}^{-1} \mathrm{sr}^{-1}\right.$ and $100 \mathrm{Mm}^{-1}$ at $355 \mathrm{~nm}$ ). Below a height of $1.0 \mathrm{~km}$, slightly larger values and a wavelength dependence of the linear particle depolarization ratio indicate the dominance of mineral dust. Compared to the pure dust conditions that were encountered during SAMUM-1 (Freudenthaler et al., 2009; Tesche et al., 2009a) the increased Ångström exponents and decreased particle depolarization ratios indicate that the dust in the boundary layer is mixed with another type of aerosol. The low values of the 355-nm lidar ratio suggest that this might be sea salt (Groß et al., 2011b).

Above $1 \mathrm{~km}$ height, increased Ångström exponents (around unity for backscatter and extinction) and lidar ratios (60-80 sr at 355 and $532 \mathrm{~nm}$ ) are indicative for a mixture of biomass-burning smoke with mineral dust (Tesche et al., 2009b). This is also found from the Falcon measurement of the chemical composition of the aerosol mixture (Lieke et al., 2011). The high concentration of small soot particles in a pure smoke plume would cause much larger lidar ratios (>100 sr). Furthermore, pure smoke particles are rather small and almost spherical and cannot cause the relatively large particle depolarization ratios of $0.14-0.20$ at 355,532 , and $710 \mathrm{~nm}$ as observed in the layer between 1.0 and $4.0 \mathrm{~km}$ height. The profiles of the volume depolarization ratio (Fig. 7e) show an increase with wavelength due to the decreasing sensitivity to molecular backscatter. However, if the particle depolarization ratio is calculated, similar values between 0.14 and 0.18 were found in the mixed dust/smoke layer at all three wavelengths. 
Fig. 8. Comparison of the HSRL measurement (orange lines, 15-s mean) during the overflight at 1620 UTC on 22 January 2008 with the evening measurement with BERTHA from 2005 to 2100 UTC (dark green lines, see Fig. 6) and a measurement with MULIS between 1600 and 1700 UTC (dashed black line, $S=70$ $80 \mathrm{sr}$ ). BERTHA backscatter (a), extinction (b), and lidar ratio profiles (c) are smoothed with the window lengths given in the respective plots.
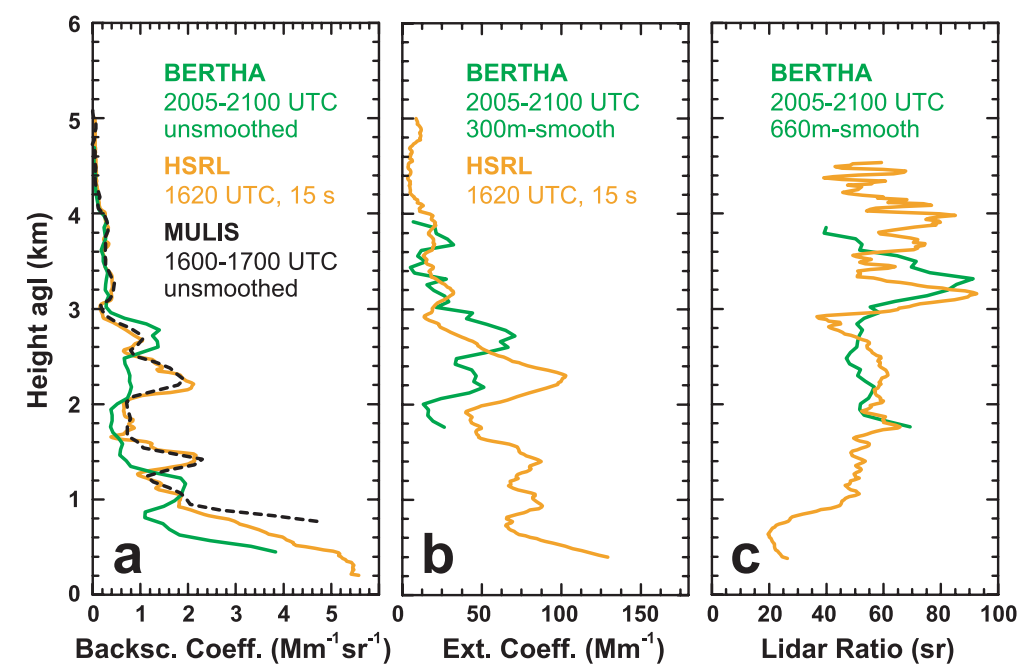

The Falcon research aircraft with the HSRL on board passed the ground site at 1620 UTC. Stable conditions allowed for a comparison of an unsmoothed 15-s mean profile from the HSRL (orange) with the 1-h mean evening measurement with BERTHA (dark green) as shown in Fig. 8. The smoothing lengths of the BERTHA profiles are given in the respective plots. We introduced this temporal delay because nitrogen Raman signals for the measurement of the extinction coefficient (which is needed for a proper comparison of the two instruments) can only be detected during the night, when the background noise of sunlight is absent (Ansmann and Müller, 2005). Thus the shift of the peaks in Fig. 8 is due to the temporal development of the aerosol layers, which is shown in Fig. 6. The dashed black line in Fig. 8a shows the analysis of a MULIS measurement between 1600 and 1700 UTC with an assumed height-dependent lidar ratio of 70-80 sr. A good agreement is found between the backscatter coefficients coincidently measured with MULIS and HSRL. However, for a comparison of the extinction coefficient and the lidar ratio only the evening measurement can be applied. A good agreement between ground-based and airborne measurements is also found for these parameters taking the different measurement times into account. AOTs computed from the HSRL extinction profiles are used by Bauer et al. (2011) to calculate the radiative forcing of the observed aerosol layers. The radiative effect of the mixed dust/smoke layers is also investigated in the modelling study by Heinold et al. (2011).

3.1.2. 6 February 2008. The measurement of 6 February 2008 is representative for the last period of the SAMUM-2 winter measurements, when no pure dust layers were detected any longer (Knippertz et al., 2011). Similarly to the first case study, an overview of the measurements of lidar, radiosonde, and Sun photometer is shown in Fig. 9.

A well-developed maritime boundary layer which can be identified by very low depolarization ratios (purple and blue in Fig. 9e) is topped by a deep smoke-dominated layer that ex- tends up to $4.5 \mathrm{~km}$ height. As shown in Fig. 1 of Knippertz et al. (2011), the shallow dust layer which was usually observed above the maritime boundary layer disappeared completely during the last days of the winter campaign. However, mineral dust still contributes to $40-60 \%$ to the measured optical parameters in the layer between 1.0 and $4.5 \mathrm{~km}$ height (see Fig. 9 of Tesche et al., 2011).

The temporal development of the aerosol stratification on 6 February 2008 is presented in Figs 9c and e. The deep smokedominated layer observed during noon splits into a layer descending from $2.5-3.0 \mathrm{~km}$ to $1.5-2.0 \mathrm{~km}$ height and a layer that extends between 3.0 and $4.0 \mathrm{~km}$ height and maintains a rather constant height. The afternoon sounding launched at 1443 UTC (Figs 9b and d) shows that the layer of clean air in the height range from 2.0 to $3.0 \mathrm{~km}$ (low backscatter and depolarization signal in Figs 9c and e) was advected from the northwest to the measurement site with wind speeds of up to $11 \mathrm{~m} \mathrm{~s}^{-1}$ (see also backward trajectories in Fig. 9a of Knippertz et al., 2011). In the lofted aerosol layers low wind speed prevailed while values between 10 and $14 \mathrm{~m} \mathrm{~s}^{-1}$ were measured in the lowermost kilometre.

Sun photometer observations during the afternoon lidar measurement (before 1400 UTC and around 1600 UTC) are in part disturbed by altocumulus clouds at $5 \mathrm{~km}$ height and above (not shown). These observations show a comparably low optical depth of around 0.2 that was also observed during the nighttime lidar measurement (bold green line in Fig. 9a). Also daytime Ångström exponents of $0.7-0.8$ are in remarkably good agreement with the lidar nighttime observations of 0.7 shown in Fig. 10d considering that a column integrated value is compared to a height-resolved one in a case of very complex aerosol stratification.

The aerosol profiles of the evening measurement of 6 February 2008, 2038-2220 UTC (right panel in Figs 9c and e), are shown in Fig. 10. The smoothing lengths of the different 


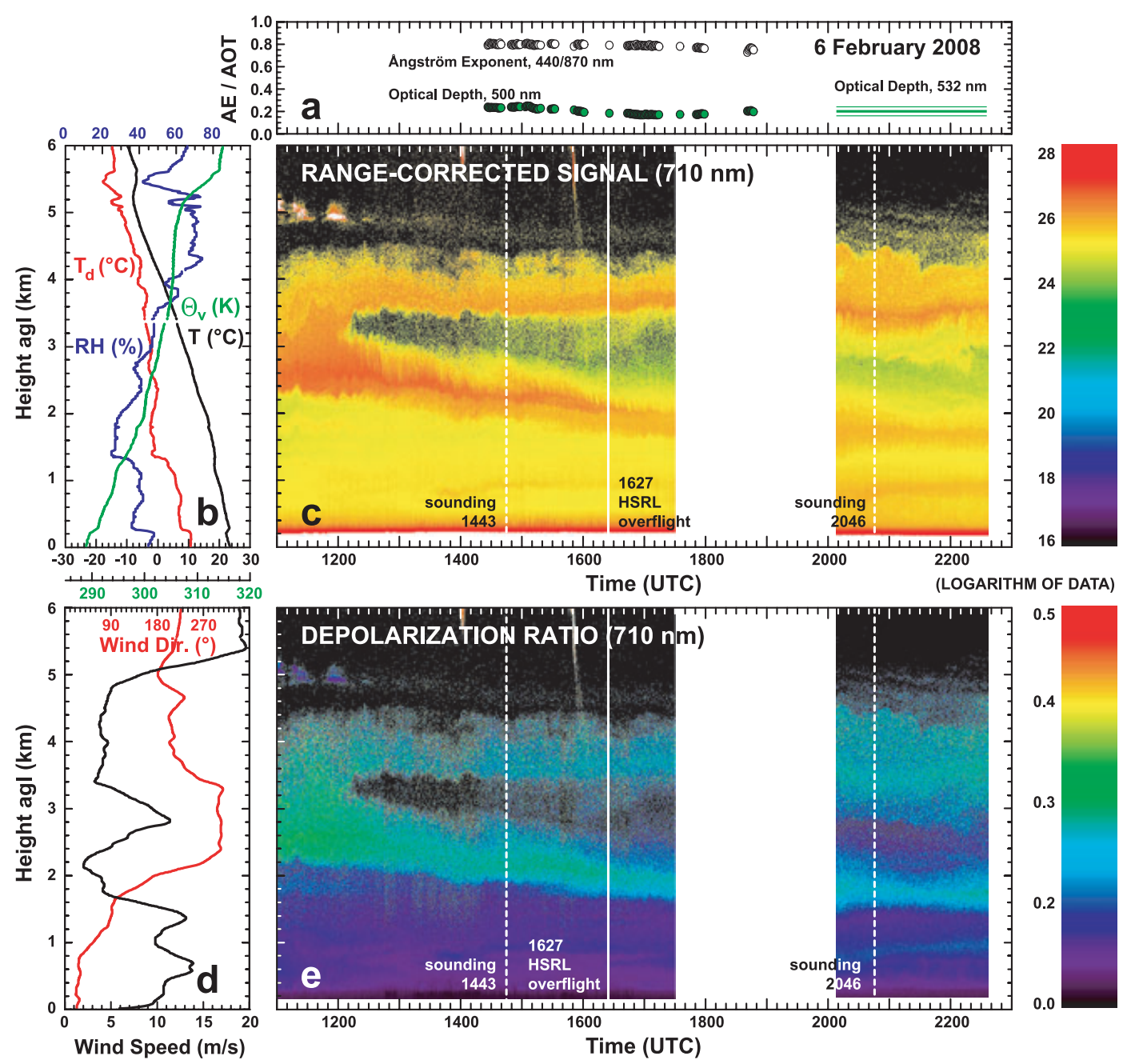

Fig. 9. Same as Fig. 6 but for the measurement on 6 February 2008, 1100-2220 UTC. The radiosonde shown in (b) and (d) was launched at 1443 UTC (left dashed lines in $\mathrm{c}$ and e). The Falcon aircraft passed the ground site at 1627 UTC (solid white lines in $\mathrm{c}$ and e).

profiles are similar to the ones discussed for the first case study of 22 January 2008. Backscatter coefficients of BERTHA (complete 1064-nm profile, $532 \mathrm{~nm}$ above $2.5 \mathrm{~km}$ and $355 \mathrm{~nm}$ above $3.0 \mathrm{~km}$ ), MULIS (532 nm below $2.5 \mathrm{~km}$ ), and POLIS (355 nm below $3.0 \mathrm{~km}$ ) show the two aerosol layers with maximum $532-\mathrm{nm}$ backscatter values of $1.5 \mathrm{Mm}^{-1} \mathrm{sr}^{-1}$ at $3.5 \mathrm{~km}$ and of $0.8 \mathrm{Mm}^{-1} \mathrm{sr}^{-1}$ at $1.7 \mathrm{~km}$ height. The minimum at $2.5 \mathrm{~km}$ height corresponds to the clean air advected from the northwest. Below $1 \mathrm{~km}$ height, the air is also very clean as indicated by the low particle backscatter with peak values of $0.4 \mathrm{Mm}^{-1} \mathrm{sr}^{-1}$ at $532 \mathrm{~nm}$. The top of the nocturnal boundary layer is indicated by the strong increase of the backscatter coefficient at a height of $0.4 \mathrm{~km}$.

The extinction profiles show high values of $120 \mathrm{Mm}^{-1}$ and $70 \mathrm{Mm}^{-1}$ at 355 and $532 \mathrm{~nm}$, respectively, in the upper layer. The lidar ratios of $80 \mathrm{sr}$ at $355 \mathrm{~nm}$ and $50-70 \mathrm{sr}$ at $532 \mathrm{~nm}$ show a recognizable wavelength-dependence that decreases with height.
Below $1.4 \mathrm{~km}$ height, the lidar ratio decreases and indicates the increasing influence of maritime particles. Pure maritime particles cause lidar ratios of 20-25 sr (Groß et al., 2011b). The 532-nm particle depolarization ratio of $0.15-0.20$ stays fairly constant throughout the entire atmospheric column indicating an evenly spread presence of mineral dust particles. From the BERTHA measurement at $710 \mathrm{~nm}$ and the POLIS measurement at $355 \mathrm{~nm}$, however, particle depolarization ratios could only be calculated for the uppermost smoke-dominated layer with backscatter coefficients larger than $1.0 \mathrm{Mm}^{-1} \mathrm{sr}^{-1}$. The obtained values again show almost no wavelengths dependence of this parameter (Groß et al., 2011a).

At 1627 UTC (solid white line in Figs 9c and e) another HSRL overflight was performed. The comparison of BERTHA measurements from 1620 to 1720 UTC and from 2010 to 2235 UTC with the observations of the airborne instrument is shown in Fig. 11. Again a good agreement between the extinction and 

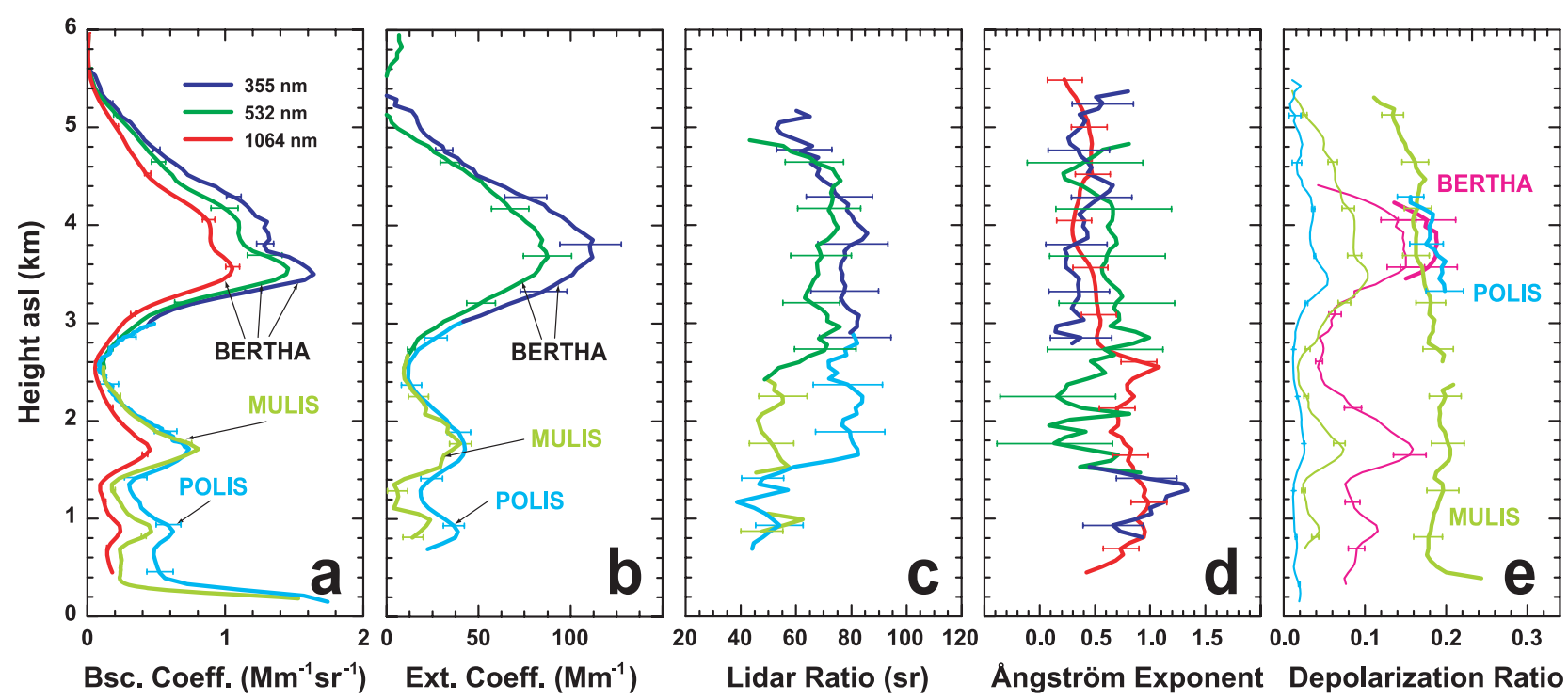

Fig. 10. Same as Fig. 7 but for the evening measurement of 6 February 2008. BERTHA measured from 2038 to 2220 UTC. POLIS and MULIS measured from 2030 to 2230 UTC.

Fig. 11. Same as Fig. 8 but for 6 February 2008. The HSRL measurement (orange lines, 37-s mean) was performed during a Falcon overflight at 1627 UTC. Coinciding BERTHA measurements between 1620 and 1720 UTC (black dashed line in a) were used to calculate a particle backscatter coefficient with an assumed lidar ratio of $60 \mathrm{sr}$. The analysis of the BERTHA evening measurement between 2010 and 2235 UTC is shown as dark green lines. The red line in (c) shows the results of the HSRL smoothed with a window length of $1200 \mathrm{~m}$.
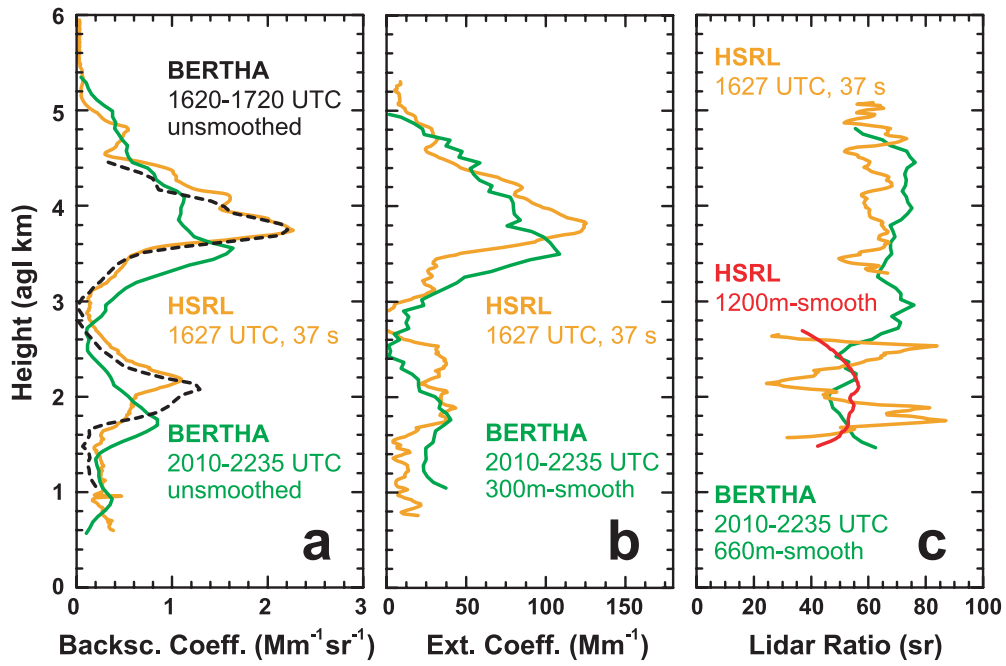

lidar-ratio profiles of the two observations is obtained, when the different measurement times are take into account. However, the noisy HSRL lidar ratios between 1.0 and $2.0 \mathrm{~km}$ height needed to be smoothed with a window length of $1200 \mathrm{~m}$ to obtain values with sufficiently low uncertainty. The comparison of the HSRLbackscatter profile to a 1-h BERTHA measurement (analysed by assuming a constant lidar ratio of $60 \mathrm{sr}$ ) between 1620 and 1720 UTC (dashed black line in Fig. 11a) also shows good agreement.

As in case of 22 January 2008, further results of the airborne in situ measurements of the aerosol size distribution and the chemical composition are presented by Weinzierl et al. (2011) and Lieke et al. (2011), respectively.

\subsection{Statistical results}

As for the SAMUM-1 observations in Morocco (Tesche et al., 2009a), mean profiles of the SAMUM-2a measurements with BERTHA were calculated from the nighttime measurements. Fig. 12 shows the results in terms of mean profiles of backscatter coefficients, extinction coefficients, lidar ratios, backscatterand extinction-related Ångström exponents, and particle depolarization ratios. Except for the latter parameter, the presented mean profiles are computed from signal profiles, which were smoothed with a window length of $660 \mathrm{~m}$. The particle depolarization ratio at $532 \mathrm{~nm}$ was extrapolated from the original measurements at $710 \mathrm{~nm}$ according to eq. (1). In the case of the 

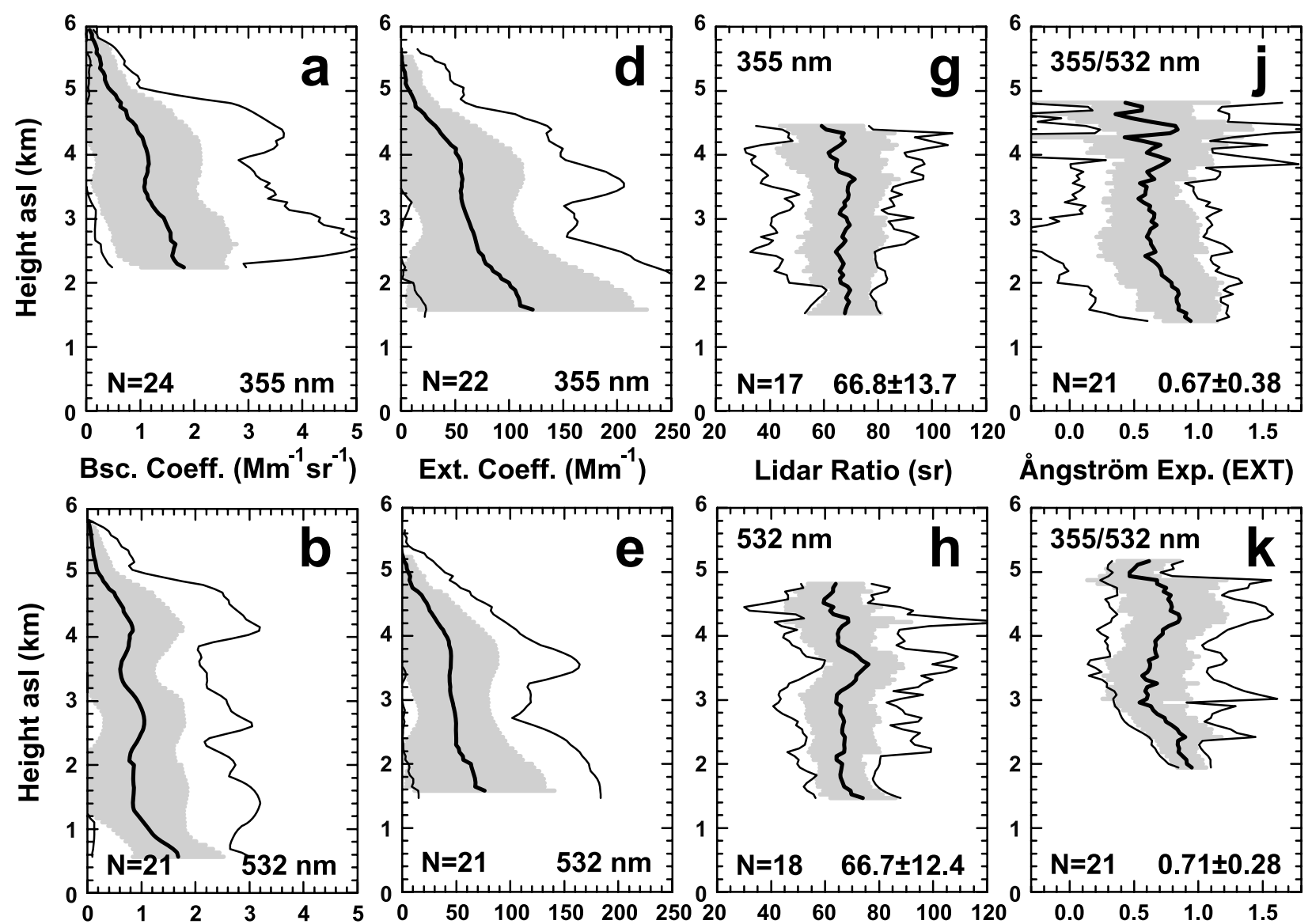

Lidar Ratio (sr)

Ångström Exp. (EXT)

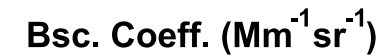

Ext. Coeff. $\left(\mathrm{Mm}^{-1}\right)$
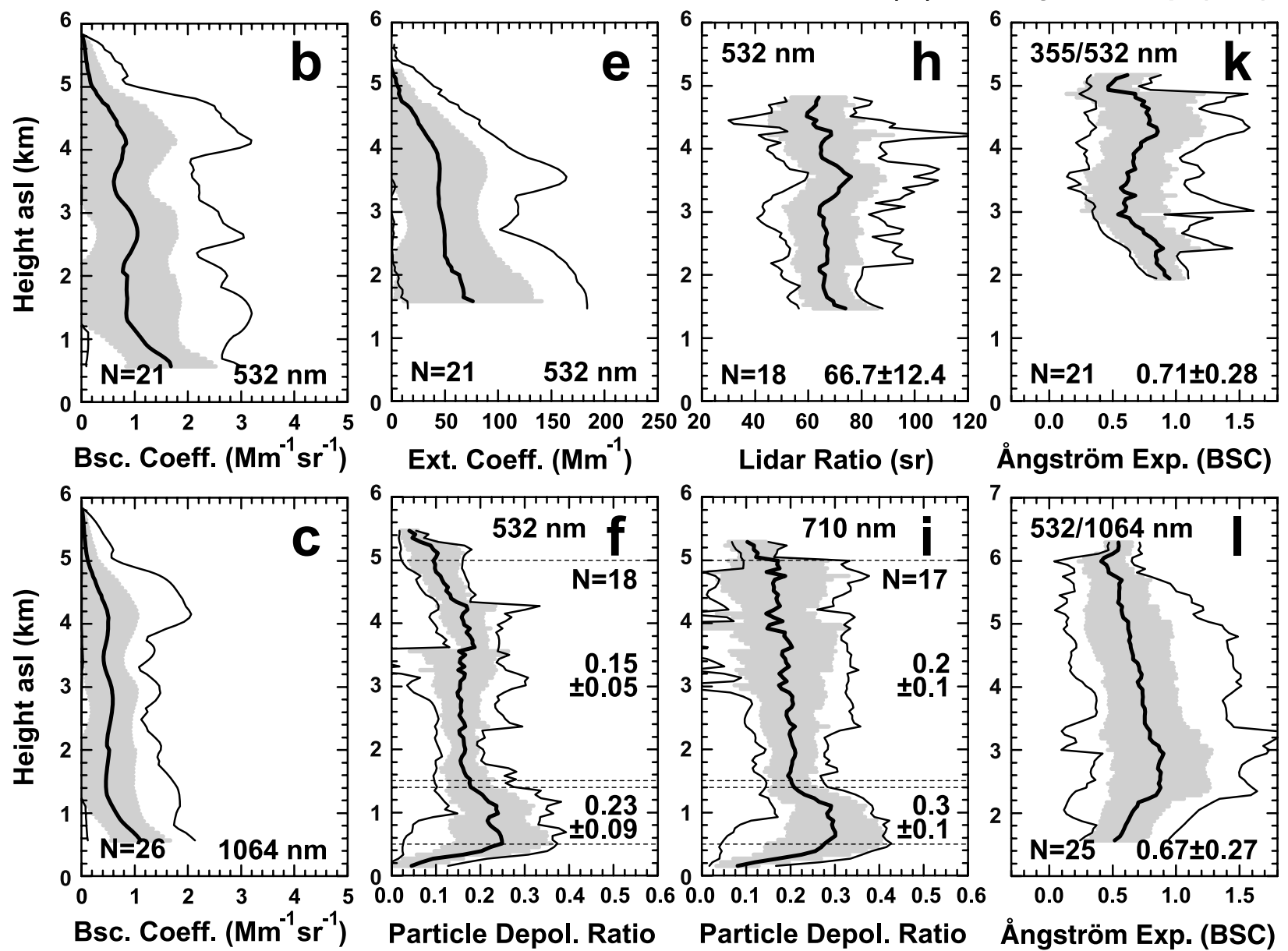

Ångström Exp. (BSC)

Lidar Ratio (sr)

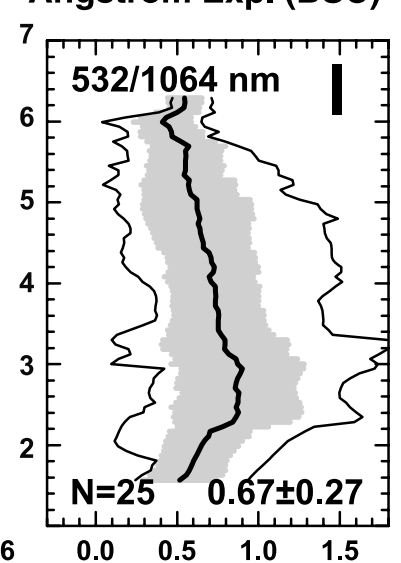

Bsc. Coeff. $\left(\mathrm{Mm}^{-1} \mathrm{sr}^{-1}\right)$

Particle Depol. Ratio

Particle Depol. Ratio

Ångström Exp. (BSC)

Fig. 12. Mean profiles (thick black lines) and standard deviations (grey areas) of the backscatter coefficient at $355 \mathrm{~nm}$ (a), $532 \mathrm{~nm}$ (b), and $1064 \mathrm{~nm}$ (c), the extinction coefficient at $355 \mathrm{~nm}$ (d) and $532 \mathrm{~nm}$ (e), the lidar ratio at $355 \mathrm{~nm}(\mathrm{~g})$ and $532 \mathrm{~nm}$ (h), the extinction-related (j) and backscatter-related Ångström exponents (k, 1), and the particle depolarization ratio at $532 \mathrm{~nm}$ (f) and $710 \mathrm{~nm}$ (i) of the SAMUM-2a nighttime measurements with BERTHA. The thin lines show the range of observed values (minimum to maximum value) for each height bin. $\mathrm{N}$ denotes the number of averaged profiles. The mean values of the mean profiles of lidar ratio, Ångström exponents, and particle depolarization ratios are given as numbers in the respective plots. The values of mean standard deviation are calculated from the grey areas, i.e., they are the mean values of the standard deviation height profiles. Mean value and standard deviation for the particle depolarization ratios are give for the height ranges $0.5-1.2 \mathrm{~km}$ and $1.5-5.0 \mathrm{~km}$ as indicated by horizontal dashed lines in (f) and (i). 
depolarization-ratio profiles, the signals were smoothed with a window length of $150 \mathrm{~m}$.

The mean backscatter coefficients between 2 and $4 \mathrm{~km}$ height were $1.4 \pm 0.2,0.8 \pm 0.1$, and $0.5 \pm 0.1 \mathrm{Mm}^{-1} \mathrm{sr}^{-1}$ at 355,532 , and $1064 \mathrm{~nm}$, respectively. The mean extinction coefficients in the same height range showed values of $66 \pm 6$ and $48 \pm$ $5 \mathrm{Mm}^{-1}$ at 355 and $532 \mathrm{~nm}$, respectively. The SAMUM-2a mean Ångström exponents show values of about $0.7 \pm 0.4$. These values are much larger than the values of $0-0.4$ observed for pure mineral dust during SAMUM-1 (Tesche et al., 2009a). However, they are also lower than typical values for biomassburning or forest fire smoke that usually vary between 1.5 and 2.0 (Wandinger et al., 2002; Balis et al., 2003; Campbell et al., 2003; Cattrall et al., 2005; Müller et al., 2005). The mean lidar ratio profiles with values of $67 \pm 14 \mathrm{sr}$ at 355 and $532 \mathrm{~nm}$ indicate that the lidar ratios were similar at both wavelength. Tesche et al. (2009b) present a method to retrieve the contribution of biomass-burning aerosol and mineral dust to measured optical properties by means of measurements of the particle depolarization ratio. This approach is analogue to the determination of the particle depolarization ratio from the volume (particles and molecules) depolarization ratio according to eq. (2). It is based on the knowledge of the dust depolarization ratio gained from SAMUM-1 (Freudenthaler et al., 2009). For SAMUM-2 during January and February 2008, Tesche et al. (2009b) estimate the contribution of mineral dust in the elevated dust/smoke layer to be in the range of $40-60 \%$. If this is considered and a dust lidar ratio of $55 \mathrm{sr}$ at 355 and $532 \mathrm{~nm}$ (Tesche et al., 2009a) is assumed, the lidar ratio of the pure smoke aerosol can be expected to be in the range of 75-85 sr to come up with values of $67 \mathrm{sr}$ for the dust/smoke mixture. This simple estimation is in agreement with the average optical data for pure biomass-burning smoke as retrieved by aerosol-type separation and presented by Tesche et al. (2009b; 2011).

Previous studies estimated the smoke lidar ratio from long term AERONET time series (60 sr at $550 \mathrm{~nm}$, Cattrall et al., 2005), from backscatter lidar measurements during DABEX (70-130 sr at $532 \mathrm{~nm}$, Pelon et al., 2008), and from micropulse lidar observations during the Southern African Regional Science Initiative (SAFARI-2000, 50-90 sr at $523 \mathrm{~nm}$, Campbell et al., 2003; McGill et al., 2003). These values are obtained with the help of radiative-transfer calculations or by adjustment of the smoke lidar ratio to retrieve extinction (backscatter $\times$ lidar ratio) profiles that are in agreement with optical depth measured with Sun photometer at the surface. In the CALIPSO data retrieval the lidar ratio of biomass-burning smoke is set to $70 \mathrm{sr}$ at $532 \mathrm{~nm}$ (Omar et al., 2009). This value was retrieved using simulations with a typical smoke size distribution derived from AERONET inversions. Direct measurements of pure biomass-burning or forest fire smoke with Raman lidar are scarce and usually describe situations of long-range transport. Measurements during DABEX (Heese and Wiegner, 2008) show values of around $75 \mathrm{sr}$ at $355 \mathrm{~nm}$. Elevated plumes of combustion smoke were observed with Raman lidar at the Maldives during INDOEX. Ansmann et al. (2000) and Franke et al. (2001, 2003) found 532-nm lidar ratios of 60-90 sr within air masses that crossed the central eastern parts of India before being advected to the measurements site. Biofuel combustion (mainly fuelwood) is dominant in this region.

Within the mixed dust/smoke layer between 1.5 and $5.0 \mathrm{~km}$ height, the particle depolarization ratios at 532 and $710 \mathrm{~nm}$ show a slight spectral variation with values of $0.15 \pm 0.05$ and $0.2 \pm$ 0.1 , respectively (Figs $12 \mathrm{f}$ and $\mathrm{j}$ ). The linear particle depolarization ratios within the lowermost $1.4 \mathrm{~km}$ of the atmospheric column indicate the dominance of mineral dust near the surface. Note that the mean values of $0.23 \pm 0.09$ at $532 \mathrm{~nm}$ and $0.3 \pm$ 0.1 at $710 \mathrm{~nm}$ are too low to represent pure dust conditions. The lower values are caused by the fact that 17 individual profiles were averaged - including the last days of the campaign during which no pure dust layers were present over Praia (see Fig. 1 of Knippertz et al., 2011). As already discussed, values in the elevated dust-dominated layer on the other hand are obviously smaller than the ones for mineral dust and larger than for pure (small and rather spherical) smoke aerosol. Section 5 presents mean values for the aerosol types observed during all SAMUM campaigns (Table 2).

\section{SAMUM-2b Observations}

From 24 May to 17 June 2008 the lidar group of IfT performed additional measurements at Praia airport to investigate the aerosol conditions west of the African continent during summer. These measurements allow for a comparison of winter and summer conditions at Cape Verde and of dust properties observed near the source regions during SAMUM-1 and in the beginning of long-range transport during SAMUM-2.

Before the case studies are discussed a brief overview of the meteorological conditions during SAMUM-2b is provided. The advection of mineral dust to the measurement site at the Cape Verde island during summer strongly depends on the occurrence of a local surface low over southern Mauritania that increases the pressure gradient between the African heat low and the Azores high. This frontier stretches over the tropical north Atlantic. Its location varies with the position of the Azores high. During the larger part of the SAMUM-2 summer measurements slow wind speed and low pressure gradients prevailed. Maritime aerosol was advected to the measurement site from northerly direction within the boundary layer. The main dust plume was located south of Cape Verde, which led to comparably low dust optical depth at the measurement site. During the periods of high optical depth, an undisturbed easterly flow with strong upperlevel wind speeds transported mineral dust from the northern African source regions to the tropical North Atlantic. During these periods, northerly flow prevailed at the lower heights and brought clean air to the measurement site at these height levels. This circulation pattern is consistent with the classical air flow 

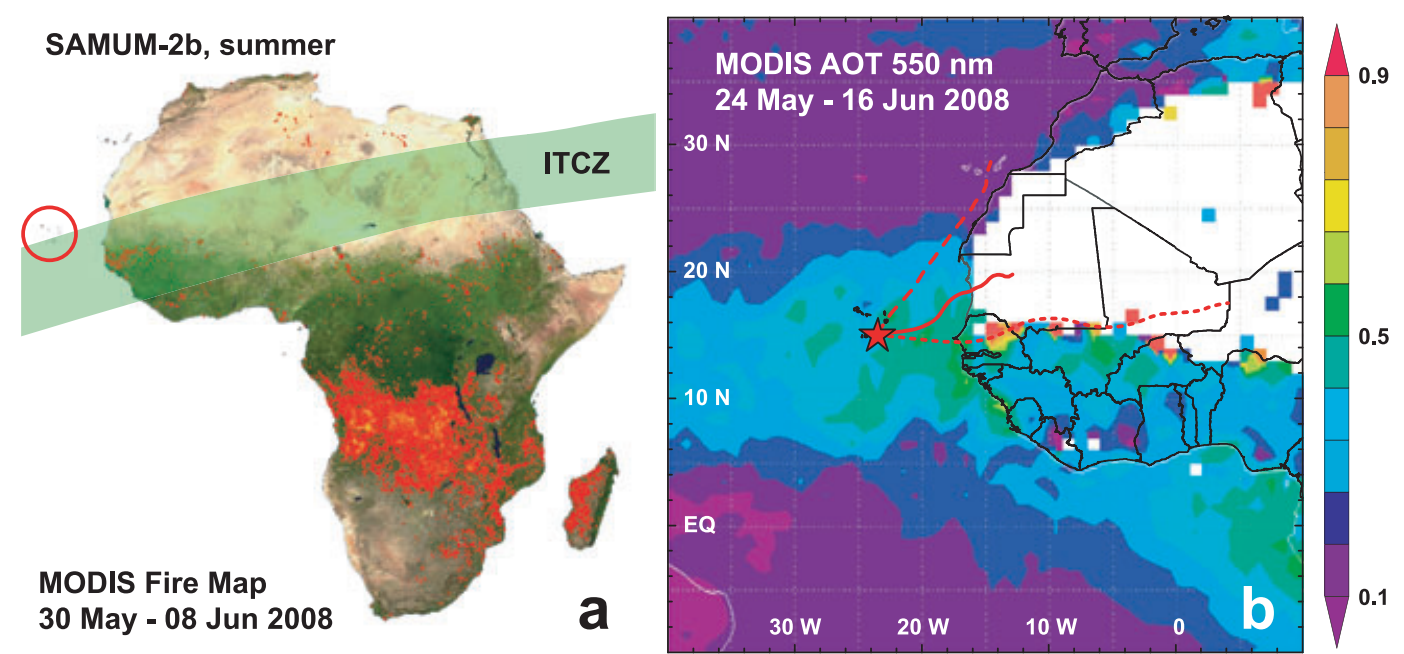

Fig. 13. Same as Fig. 5 but for the summer measurements of SAMUM-2. The ITCZ now spans over North Africa while the area of biomass-burning moved southward (a). Thus no biomass-burning smoke is transported to Cape Verde. The map of MODIS 550-nm AOT (b) shows two distinct plumes of dust off the West African coast and of smoke over the Gulf of Guinea. No mixture of these aerosol types occurs. The example trajectories (red lines in b) that arrive within the observed aerosol layer at $500 \mathrm{~m}$ (dashed), $2500 \mathrm{~m}$ (solid), and $4500 \mathrm{~m}$ (short dashed) above ground level show that air is transported to Cape Verde from North Africa and the Atlantic ocean.

pattern for Saharan air plumes as described by Karyampudi et al. (1999).

Figure 13 displays the location of active fires and the aerosol conditions as observed with MODIS during the period of the SAMUM-2 summer campaign. The figure is analogue to Fig. 5. In contrast to winter conditions with one huge aerosol plume extending from the equator to about $15^{\circ} \mathrm{N}$, the MODIS mean AOT map now shows two distinct areas of increased optical depth. One is located at the equator west of the region of summertime biomass-burning activity, which is shown as red area in the left panel of the figure. The other plume is located in a band between 5 and $25^{\circ} \mathrm{N}$ southwest of the western Saharan desert. The green-shaded area in Fig. 13 represents the movement of the ITCZ during summer. Compared to winter, the ITCZ is located far to the north and represents an impenetrable barrier that separates the dust regions in North Africa from the areas of biomass-burning activity in Central Africa. Therefore, pure dust is transported over the tropical North Atlantic during summer, passing the Cape Verde islands on its way to the Caribbean. The example trajectories (red lines in of Fig. 13b) show that in the boundary layer $(0.5 \mathrm{~km}$, dashed line $)$ air advected over Praia airport usually comes from the Atlantic ocean while at larger heights $(2.5 \mathrm{~km}$, solid and $4.5 \mathrm{~km}$, dotted $)$ the trajectories originate over desert areas.

Similarly to Fig. 1a of Knippertz et al. (2011), Fig. 14 gives an overview of the aerosol layering observed during the summer campaign. Usually a $0.5-1.0 \mathrm{~km}$ deep maritime boundary layer (blue bars) topped by a 4-5 km deep mineral dust layer (red bars) was observed. The time series of optical depth $(532 \mathrm{~nm}$, red dots) and Ångström exponents (532/1044 nm, white dots) obtained with the SP1A photometer corroborates the lidar find- ings. The low Ångström exponents of 0-0.3 represent large sea salt particles and mineral dust. The arrival of an elevated dust layer in the night from 3 to 4 June 2008 is discussed first. The second case study describes the arrival of the dust plume in the evening of 14 June 2008. Towards the end of the campaign the performance of BERTHA degraded due to problems with the laser.

During the summer measurements, BERTHA's 532-nm rotational-Raman channels (Arshinov et al., 2005; Tesche et al., 2009a) were operational and allowed for a retrieval of backscatter and extinction coefficients with the Raman method during daytime. Thus the 532-nm volume depolarization ratio profile estimated from the measurements at $710 \mathrm{~nm}$ could be verified by comparing the corrected 532-nm backscatter profile (from 532nm elastic backscatter and 607-nm vibrational Raman backscatter, see Section 2.1 and Mattis et al., 2009; Tesche et al., 2009a) to the results of the rotational-Raman channels (that incorporate an additional elastic-backscatter channel). Because its PMT broke during the first days of the summer measurements, the 1064-nm channel was operational only during few days in the end of the measurement period. This results in bad statistics for the 1064-nm backscatter coefficient and the 532/1064$\mathrm{nm}$ backscatter-related Ångström exponent shown later in this section.

\subsection{Case studies}

The evening measurements of 3 and 14 June 2008 are representative for the observations during the summer campaign. The two measurements were performed during the arrival of distinct Saharan dust plumes which can be identified by an increase in 

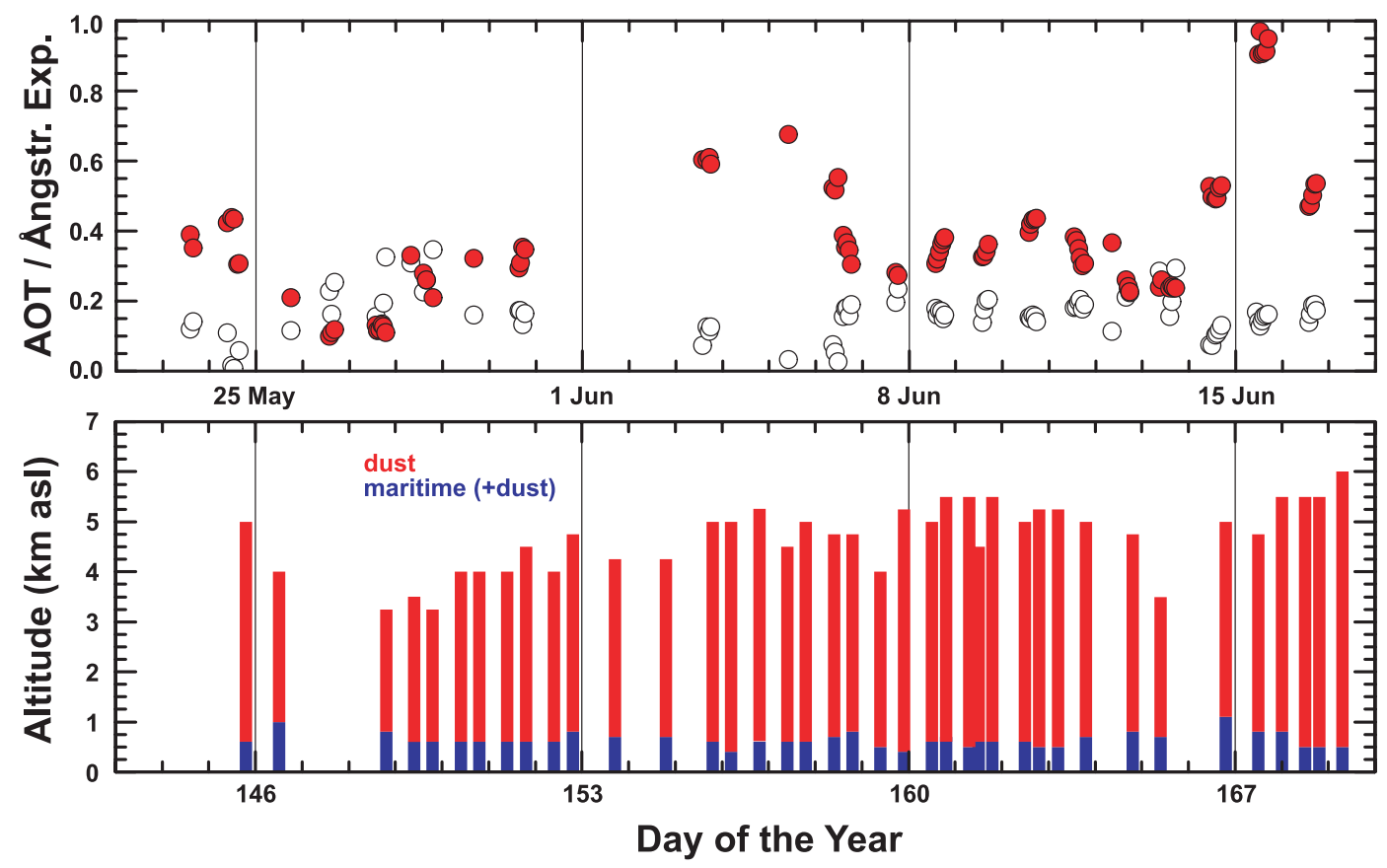

Fig. 14. Time series of 1-h mean values of (a) aerosol optical thickness (red, $532 \mathrm{~nm}$ ) and Ångström exponents (white, 532/1044 nm) measured with the SP1A Sun photometer and (b) aerosol layer depth from lidar measurements observed during May-June 2008. The figure is similar to the upper panels in Fig. 1 of Knippertz et al. (2011). Blue colours in (b) represent the maritime boundary layer while red denotes mineral dust. The discrimination was performed subjectively with the help of measurements of the linear depolarization ratio. Column Ångström exponents below 0.3 confirm the dominance of mineral dust and sea salt aerosol.

optical depth and very low Ångström exponents (Fig. 14). Due to a favourable airflow, theses measurements were used for the validation of CALIOP measurements during overpasses in the vicinity (170 km on 3 June 2008 and $480 \mathrm{~km}$ on 14 June 2008) of the measurement site at Cape Verde (Wandinger et al., 2010). The results shown in this section are in agreement with two SHADE observations in September 2000 (Léon et al., 2003).

4.1.1. 3 June 2008. On 3-6 June 2008 dusty air was transported to Cape Verde by increased upper-level winds from easterly to southeasterly directions. At ground level, slow northerly flow transported clean maritime aerosol to the measurement site. The observations of Sun photometer, lidar, and radiosonde in the night of 3-4 June 2008 are shown in Fig. 15. Daytime photometer-derived optical depth of 0.6 (green dots in a) are in good agreement with the lidar observations of 0.60-0.63 during the night (green horizontal lines in a). The lidar-derived optical depth was obtained by integration of the 532-nm extinction coefficient in the height range from 1 to $5 \mathrm{~km}$. An optical depth of 0.05 which is usually observed for purely maritime boundary layers (Kaufman et al., 2001) was added for the lowermost kilometre of the atmospheric column. The low Ångström exponents of 0.1 (white dots in a) clearly indicate the dominance of large mineral dust and sea-salt particles.

The lidar measurement documents the descent of the top of the maritime boundary layer from 1.0 to $0.5 \mathrm{~km}$ height during the night. At $2.5-5.0 \mathrm{~km}$ on the other hand the arrival of a deep dust layer is visible in the time-height displays of the 532-nm range-corrected signal (c) and the 710-nm volume depolarization ratio (e) at around 2130 UTC. The stratification observed in the lidar measurement is also visible in the profiles of the 2319UTC sounding (shown in $b$ and $d$, white dashed line in $c$ and e). The maritime boundary layer is characterized by wind that turns from north to east with height and shows speeds above $10 \mathrm{~m} \mathrm{~s}^{-1}$. An inversion and a strong decrease in relative humidity mark the top of this layer. The deep dust plume is divided by an inversion and a layer of rather slow winds (below $5 \mathrm{~m} \mathrm{~s}^{-1}$ ). This step is also visible in the lidar plots. In the lower dust layer $(1.0-2.0 \mathrm{~km})$ easterly winds with speeds above $10 \mathrm{~m} \mathrm{~s}^{-1}$ dominate, while slightly slower winds from east-southeasterly direction prevail in the upper layer $(2.5-5.0 \mathrm{~km})$. As found during other observations, the top of the dust plume is marked by steps in the profiles of temperature and virtual potential temperature.

The lidar profiles corresponding to the 2330-0220 UTC time period (between the black lines in Figs $15 \mathrm{c}$ and e) are shown in Fig. 16. All profiles are smoothed with a window length of $660 \mathrm{~m}$, except for the depolarization profiles, which are smoothed with $150 \mathrm{~m}$ window length. The backscatter profiles obtained with the rotational-Raman channels (light green) and the regular vibrational-Raman channel (dark green) are in good agreement. This corroborates the fact that a reasonable 532-nm volume depolarization ratio profile (needed for the correction of polarization-dependent receiver transmission) was obtained 


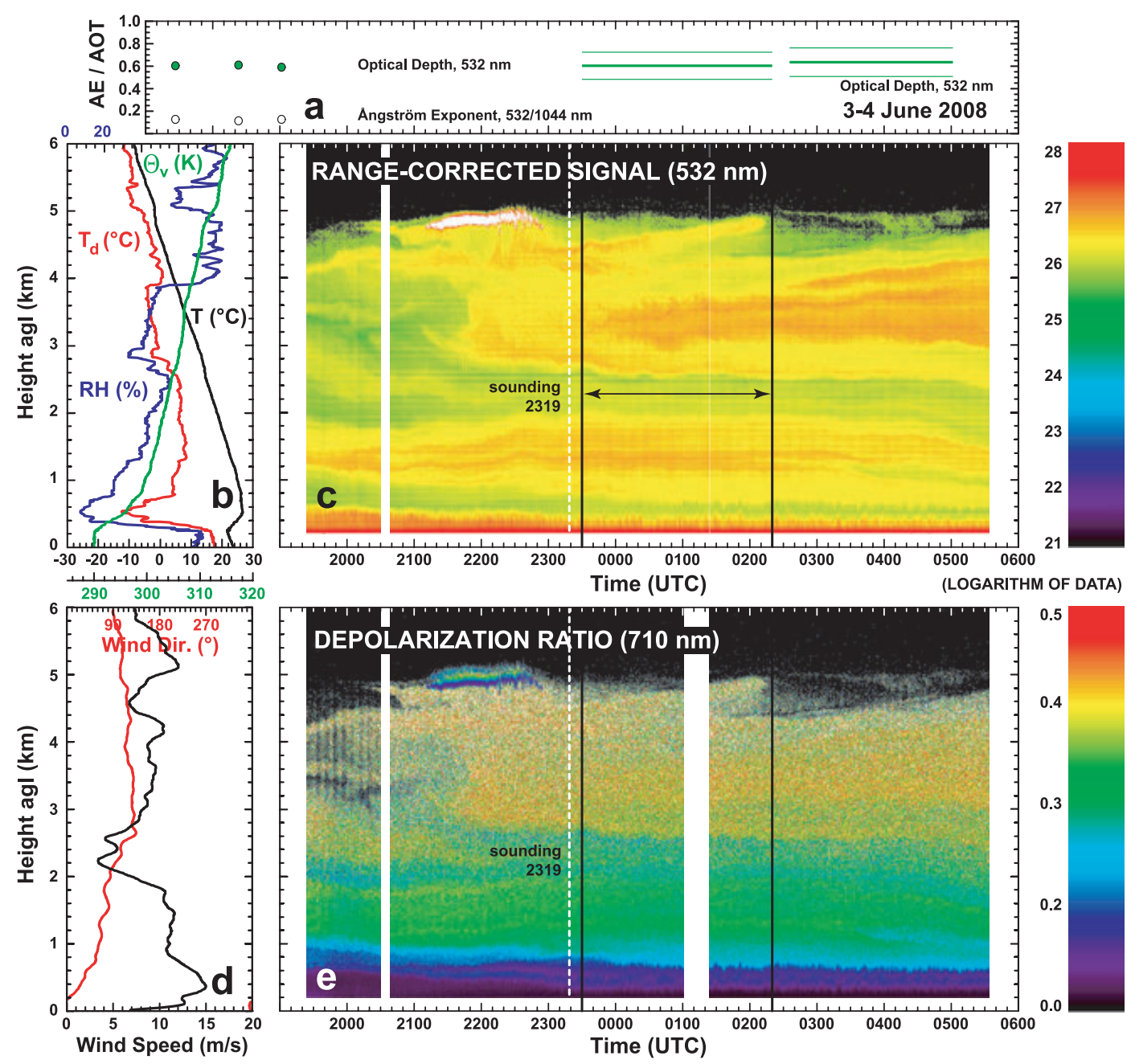

Fig. 15. Same as Fig. 6 but for the nighttime measurement of 3-4 June 2008, 1924-0532 UTC. The radiosonde (b and d) was launched at 2319 UTC (dashed white line in c and e). The interval 2330-0220 UTC (between the black lines) was chosen for the analysis presented in Fig. 16.

from the measurements at $710 \mathrm{~nm}$ (Section 2.1). This is also confirmed by $532-\mathrm{nm}$ particle depolarization ratios (Fig. 16e) of $0.29-0.35$ that are similar to the SAMUM-1 observations of $0.31 \pm 0.03$ for pure dust (Freudenthaler et al., 2009). As observed within the dust layers that were investigated during the winter measurements of SAMUM-2, values of the particle depolarization ratio of 0.4 at $710 \mathrm{~nm}$ point to a wavelengthdependence of the dust depolarization ratio (Groß et al., 2011a). Even though a step is visible in the profile of the volume depolarization ratio and the corresponding time-height display in Fig. 15e, the particle depolarization ratio profiles show rather constant values throughout the entire dust plume. Again, this emphasizes the necessity to strictly distinguish between the volume and particle depolarization ratio. Within most of the literature the vague term depolarization ratio is used.

The elevated pure dust layer that stretches from 3 to $5 \mathrm{~km}$ height shows wavelength-independent backscatter coefficients of $3 \mathrm{Mm}^{-1} \mathrm{sr}^{-1}$. The weaker, lower layer at $1-2 \mathrm{~km}$ height only shows values of $2 \mathrm{Mm}^{-1} \mathrm{sr}^{-1}$. 355-nm backscatter profiles were only trustworthy above $2.5 \mathrm{~km}$ due to problems with the overlap of laser beam and receiver field-of-view. The extinction coefficients also show no wavelength dependence with maximum values of $200 \mathrm{Mm}^{-1}$ in the upper layer. Consequently, Angström exponents of backscatter and extinction vary around zero (in both layers). Lidar ratios of around $60 \mathrm{sr}$ at 355 and $532 \mathrm{~nm}$ were found in the upper layer and also seem to be valid in the lower layer (dark green line in c). This is in fair agreement with SAMUM-1 observations of $55 \pm 5$ sr (Tesche et al., 2009a).

Overall, the observations of 3 June 2008 suggest that the optical properties of mineral dust are not altered during the first days of intercontinental transport. This is in agreement with CALIPSO observations (Liu et al., 2008a,b). However, the 532$\mathrm{nm}$ lidar ratio of 55-60 sr retrieved from our ground-based measurements is considerably larger than the value of $40 \mathrm{sr}$ that is 

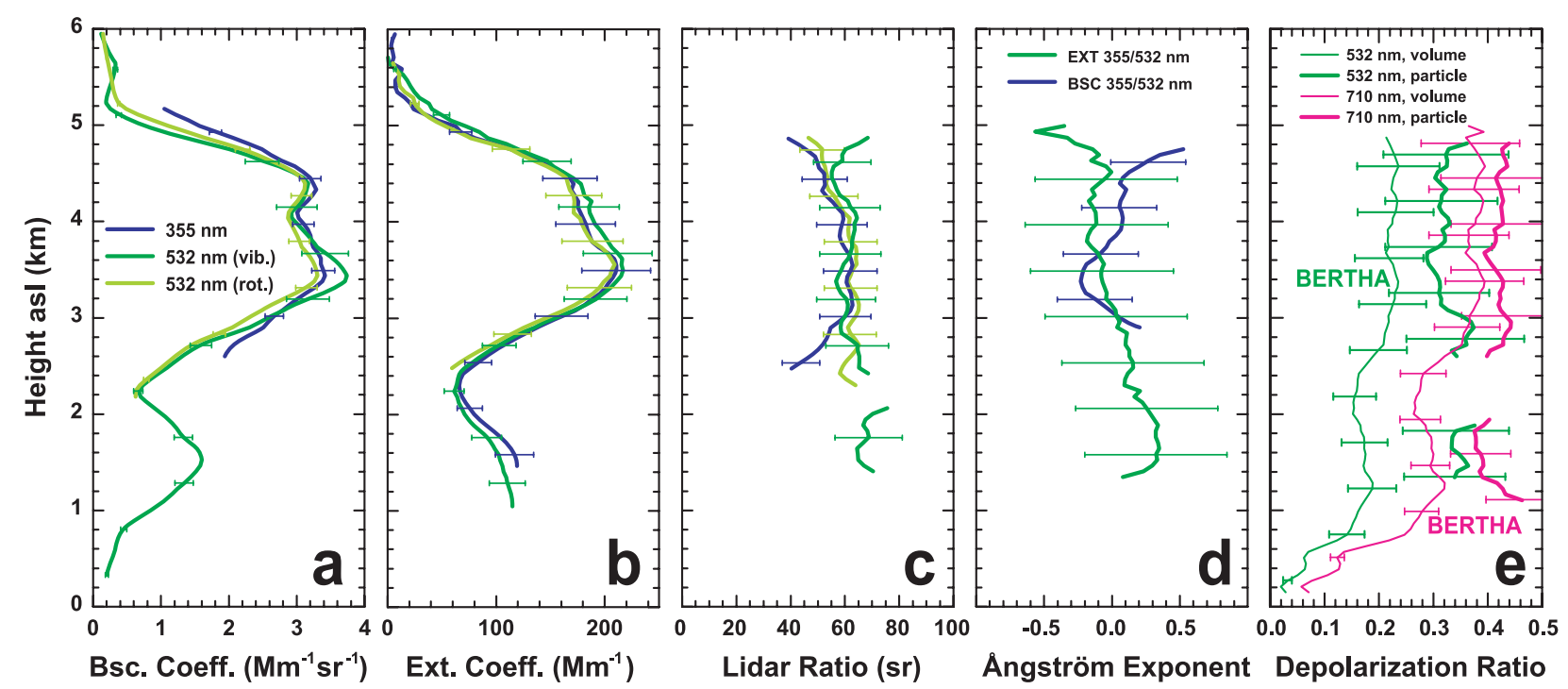

Fig. 16. Same as Fig. 7 but for the nighttime measurement of 3-4 June 2008, 2330-0220 UTC (between the black lines in Fig. 15). All profiles are measured with BERTHA and smoothed with a window length of $660 \mathrm{~m}$. Depolarization ratios at $532 \mathrm{~nm}$ are retrieved from measurements at $710 \mathrm{~nm}$ by using eq. (1).

assumed in the CALIPSO retrieval (Omar et al., 2009, 2010). An explanation of this discrepancy based on the SAMUM-2b measurements at Cape Verde and multiple-scattering calculations is given by Wandinger et al. (2010). The study shows that the underestimation of the size of the dust particles in the CALIPSO particle model leads to an underestimation of the multiple-scattering effect.

4.1.2. 14 June 2008. Due to a westward-bulge of the African heat low easterly to southeasterly flow prevailed since 13 June 2008 and led to advection of mineral dust from Mali and Mauritania to Cape Verde. The arrival of a dust plume is captured by an increase in optical depth during 14 June 2008 (see Fig. 14). The evening measurement of 14 June 2008 2133-2303 UTC is shown in Fig. 17 together with profiles of the radiosonde launched at 2315 UTC and the optical depth calculated from the 532-nm extinction profile. In the display of the volume depolarization ratio a dust layer stretches from 1 to $5 \mathrm{~km}$ height. The maritime boundary layer beneath is characterized by low depolarization ratios. As before, this discrimination is not possible by only considering the intensity of the backscattered signal. Despite showing a similar turning of wind direction with height as observed on 3-4 June 2008 the sounding now shows rather low wind speed (below $10 \mathrm{~m} \mathrm{~s}^{-1}$ ) in the maritime boundary layer. Eaterly winds prevail within the homogeneous dust layer. The wind speed shows an increase from 13 to $22 \mathrm{~m} \mathrm{~s}^{-1}$ with height. Daytime Sun-photometer measurements show a 532-nm optical depth of 0.51 and a 532/1044-nm Ångström exponent of 0.1 (Fig. 14). These values are in good agreement with the evening lidar observations shown in Fig. 17a and again demonstrate the temporal (spatial) homogeneity of dust conditions at Cape Verde. An in- tegration of the 532-nm extinction profile with an optical depth of 0.05 added for the maritime boundary layer leads to a value of $0.48 \pm 0.10$.

Profiles of backscatter, extinction, lidar ratio, Ångström exponent, and depolarization ratio are shown in Fig. 18. The smoothing lengths are the same as for the first case study. The evening measurement of 14 June 2008 is one of few during which the 1064-nm backscatter channel was operational. Maximum backscatter coefficients of $2.6 \mathrm{Mm}^{-1} \mathrm{sr}^{-1}$ were observed at this wavelength. Extinction coefficients again show no wavelength dependence with maximum values of $130 \mathrm{Mm}^{-1}$. Lidar ratios of $55 \mathrm{sr}$ at 355 and $532 \mathrm{~nm}$ are identical to the observations of pure dust in Morocco during SAMUM-1 (Tesche et al., 2009a). Particle depolarization ratios are $0.28-0.34$ and $0.36-0.44$ at 532 and $710 \mathrm{~nm}$, respectively. These large values are typical for mineral dust particles. Again, we observed a wavelength dependence of this parameter.

\subsection{Statistical results}

Corresponding to Fig. 12 mean profiles of the SAMUM-2b measurements are presented in Fig. 19. Due to the breakdown of the PMT of the 1064-nm channel, only few backscatter profiles could be obtained during the last days of the measurement campaign. The SAMUM- $2 \mathrm{~b}$ mean backscatter coefficients in the central part of the pure dust layer between 2 and $4 \mathrm{~km}$ height showed values of $1.4 \pm 0.2,1.4 \pm 0.1$, and $1.1 \pm 0.1 \mathrm{Mm}^{-1} \mathrm{sr}^{-1}$ at 355,532 , and $1064 \mathrm{~nm}$, respectively. The mean dust extinction coefficients at 355 and $532 \mathrm{~nm}$ were about $80 \pm 6 \mathrm{Mm}^{-1}$. Mean lidar ratios of $53 \pm 10 \mathrm{sr}$ and $54 \pm 10 \mathrm{sr}$ at 355 and $532 \mathrm{~nm}$, 


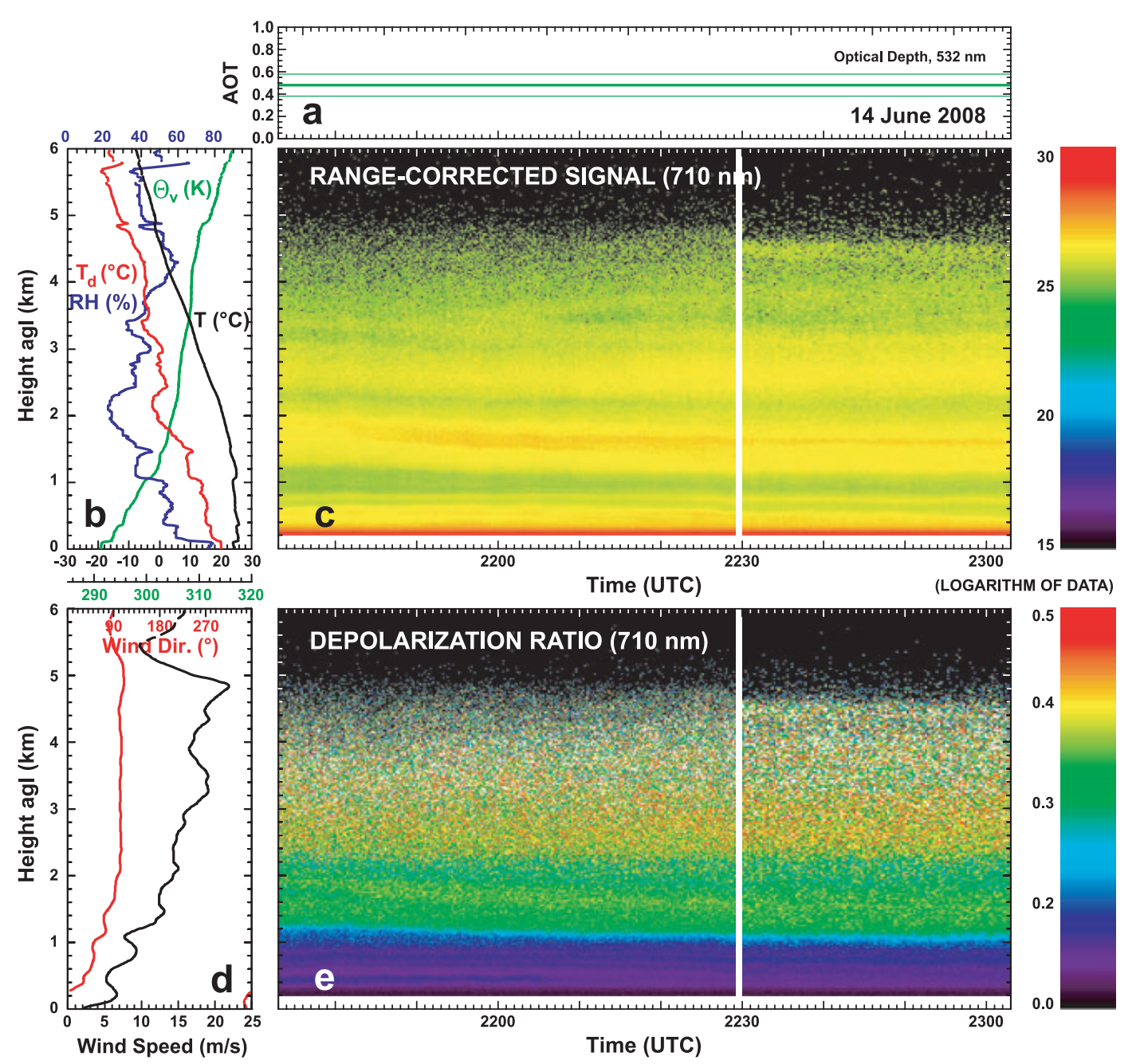

Fig. 17. Same as Fig. 6 but for the evening measurement of 14 June 2008, 2133-2317 UTC. The radiosonde (b and d) was launched at 2315 UTC after the end of the lidar measurement.

respectively, were similar to the findings of SAMUM-1 (Tesche et al., 2009a). The latter are indicated as dashed grey lines in Figs $19 \mathrm{~g}, \mathrm{~h}, \mathrm{j}, \mathrm{k}$, and 1 (adopted from Fig. 15 of Tesche et al., 2009a).

In contrast to SAMUM-1, a 1064-nm lidar ratio could not be retrieved due to the coexistence of a maritime boundary layer and an elevated dust layer. These inhomogeneous conditions complicate the combination of height-integrated Sun photometer measurements with height-resolved lidar observations. The backscatter- and extinction-related Ångström exponents within the dust layers are also comparable to the observations in Morocco. Only the 532/1064-nm backscatter-related Ångström exponent is slightly larger than the one observed during SAMUM-1. However, this deviation might be caused by the small number of measurements with the 1064-nm channel.

The most important finding of the summer measurements is the wavelength dependence of the particle depolarization ratio.
We observed values of $0.31 \pm 0.10$ at $532 \mathrm{~nm}$ and $0.37 \pm 0.07$ at $710 \mathrm{~nm} .710-\mathrm{nm}$ volume depolarization ratios were measured with much higher accuracy compared to SAMUM-1. They allow for a calculation of particle depolarization ratios with sufficiently small error bars small to draw this conclusion. Because the correction of the 532-nm elastic backscatter channel with the extrapolated 532-nm volume depolarization ratio yields results that are in good agreement with the independently retrieved 532-nm rotational-Raman backscatter coefficients, we are quite confident that the 532-nm volume depolarization ratio profiles and thus the obtained particle depolarization ratios are reliable within their error bars of 12-30\% (increasing with height due to signal noise). Because the intensive parameters of SAMUM-1 and SAMUM-2b are in good agreement (Fig. 19) and the 710-nm depolarization ratios measured at Cape Verde are much more reliable compared to the ones measured in Morocco (Freudenthaler et al., 2009), we are confident that the 710-nm 

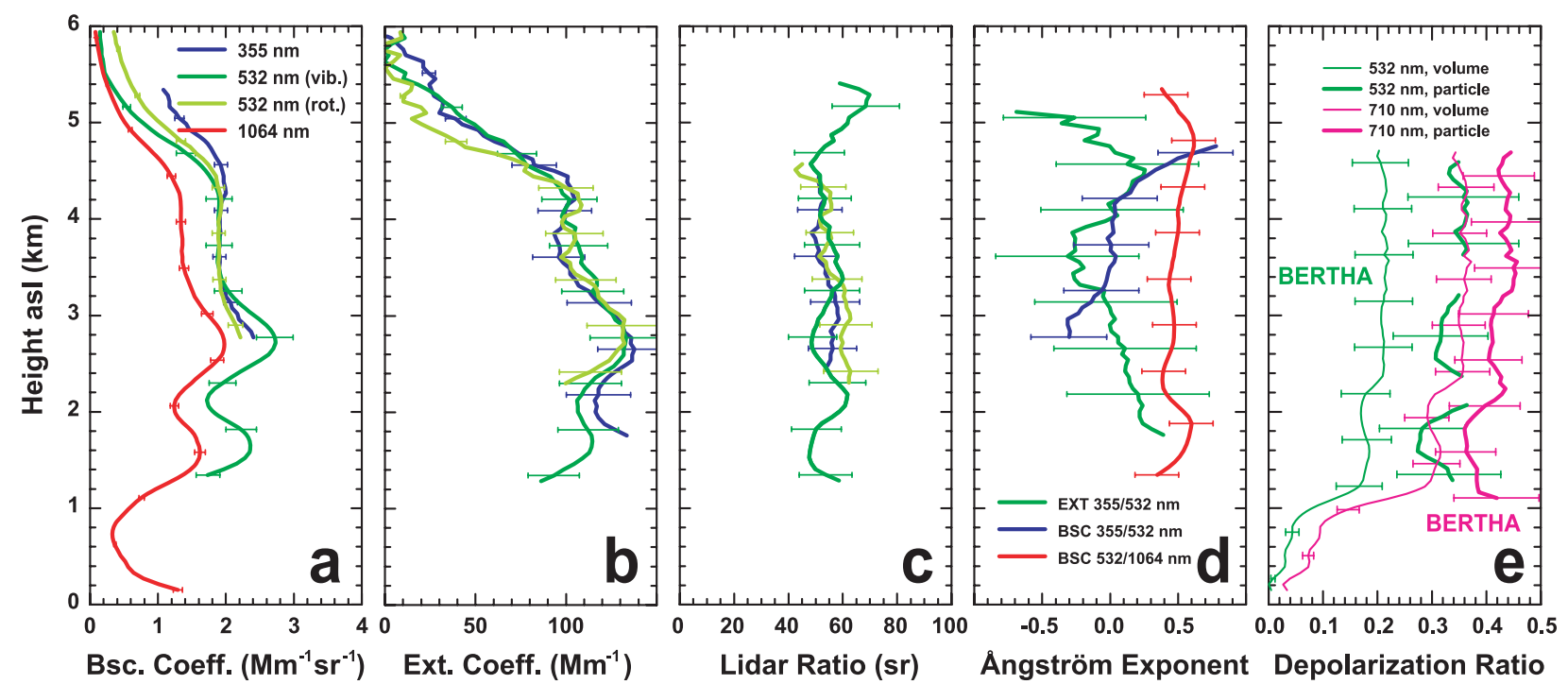

Fig. 18. Same as Fig. 16 but for the nighttime measurement of 14 June 2008, 2133-2317 UTC.

particle depolarization ratio of $0.37 \pm 0.07$ also represents the SAMUM-1 measurements close to the dust source, i.e., pure dust conditions.

\section{Overall findings of the SAMUM campaigns}

The complete SAMUM data set enables the comparison of optical and geometrical properties of mineral dust close to the source regions in Morocco (SAMUM-1) and after the first thousand kilometres of long-range transport over the Atlantic ocean (SAMUM-2) to investigate possible aging effects. Table 2 summarizes these findings. The SAMUM observations resulted in mean light extinction profiles under ambient conditions. Such information is of value for the validation of aerosol transport modelling (Heinold et al., 2011). The mean dust extinction coefficients between 2 and $4 \mathrm{~km}$ height asl were $97 \pm 23 \mathrm{Mm}^{-1} \mathrm{sr}^{-1}$ at 355 and $532 \mathrm{~nm}$ during SAMUM-1. Individual observations showed values as high as $250 \mathrm{Mm}^{-1} \mathrm{sr}^{-1}$ at the two wavelengths (Tesche et al., 2009a). The respective values during SAMUM$2 \mathrm{~b}$ (also for pure dust) varied around $80 \mathrm{Mm}^{-1} \mathrm{sr}^{-1}$. Individual measurements now even exceeded the SAMUM-1 maximum extinction coefficient of $250 \mathrm{Mm}^{-1} \mathrm{sr}^{-1}$ (Fig. 19d and e). The measurements of SAMUM-2a revealed wavelength-dependent mean total extinction coefficients of $66 \pm 6 \mathrm{Mm}^{-1} \mathrm{sr}^{-1}$ at $355 \mathrm{~nm}$ and $48 \pm 5 \mathrm{Mm}^{-1} \mathrm{sr}^{-1}$ at $532 \mathrm{~nm}$. Note that at the height range of $2-4 \mathrm{~km}$ asl, mineral dust contributes to $40-60 \%$ to the measured total extinction coefficients during SAMUM-2a (Tesche et al., 2009b; 2011).

The height of the aerosol layer top showed comparably little variation (line 5 in Table 2). The depth of the layers of different aerosol types on the other hand showed huge differences (line 14 in Table 2). Frequency distributions of the depth of the dust layers observed during summer in Morocco (grey) and at Cape Verde (white) are shown in Fig. 20d. There is little difference between the conditions close to the source region and about 1000 $\mathrm{km}$ away to the west with layers usually showing depth between 3 and $5 \mathrm{~km}$. Figure 20 also shows frequency distributions of the aerosol layer top height for observations in winter 2008 (a) and in summer 2008 (b) as well as of the respective depths of the dust layer and the mixed dust/smoke layer during winter (c). Summer aerosol layers showed on average a larger top height with a distinct maximum at 5-6 km. During winter, the aerosol layer maximum height was located between 3 and $6 \mathrm{~km}$. Sometimes rather shallow aerosol layers extending up to $1-3 \mathrm{~km}$ only were observed. Low aerosol layer top heights represent pure dust conditions with no elevated smoke-dominated layer (Fig. 20c). These findings reflect differences in convective processes over the Sahara and Central Africa during summer and winter.

The mean 500-nm AOT measured with Sun photometer was similar for all three campaigns with values between 0.3 and 0.4 (line 4 in Table 2). Figure 21 gives a summary of the Sun photometer observations during SAMUM. The findings of SAMUM-1 (left-hand panel, AERONET) are discussed in Tesche et al. (2009a) and only given for completeness here. Even though the SAMUM-2 histograms of AOT during winter (middle panel, SSARA and AERONET) and summer (right-hand panel, SP1A) look quite similar, the summertime mean AOT of 0.4 at $502 \mathrm{~nm}$ is slightly higher. The distribution of the Ångström exponent shows two peaks during winter. Small values represent the periods of pure mineral dust without elevated dust/smoke layers. The presence of the latter is indicated by Ångström exponents between 0.4 and 0.8. During summer the Ångström exponent histogram shows a clear dominance of mineral dust. Now, only one deep dust layer is present and easily identified 

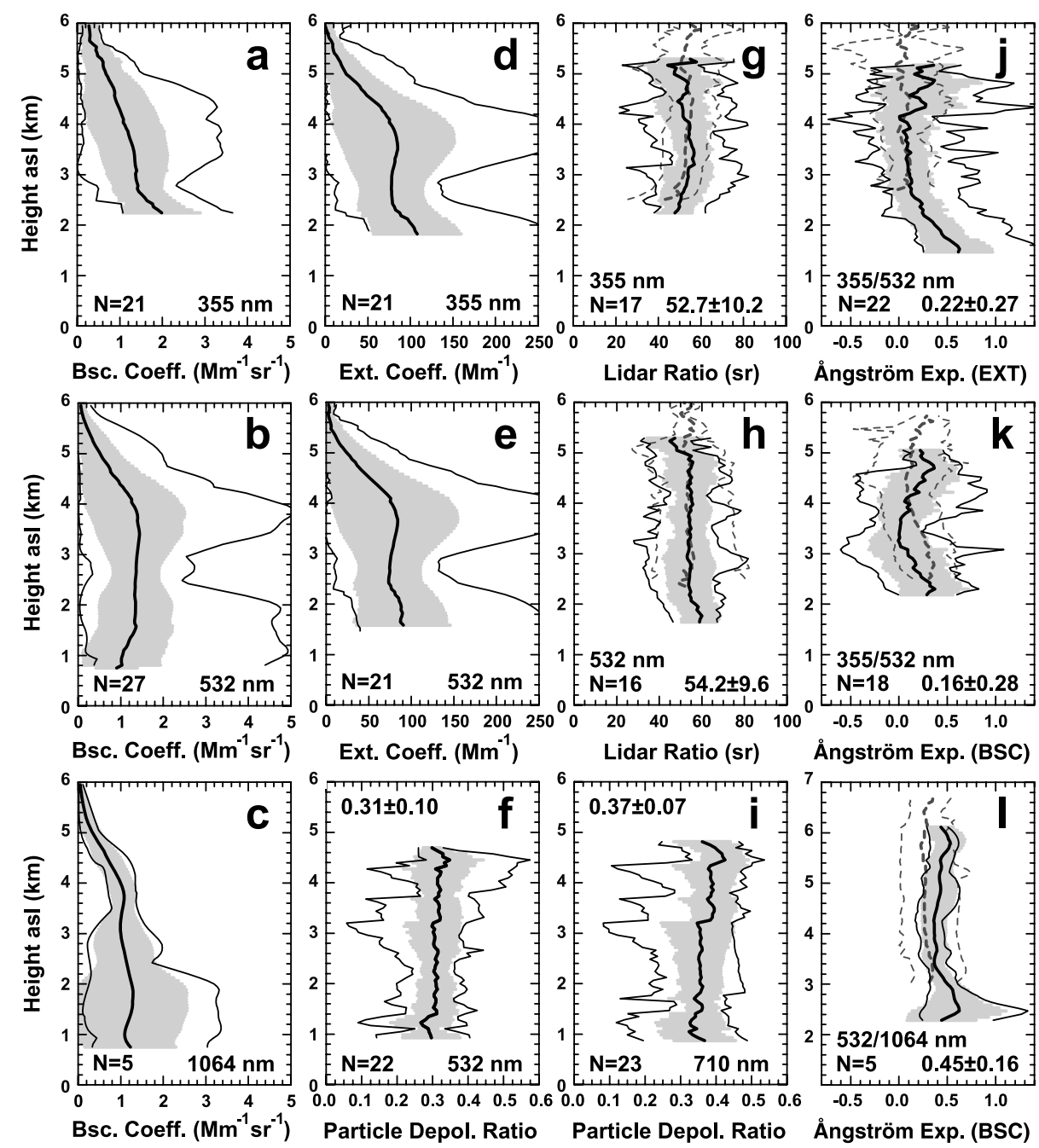

Lidar Ratio (sr)
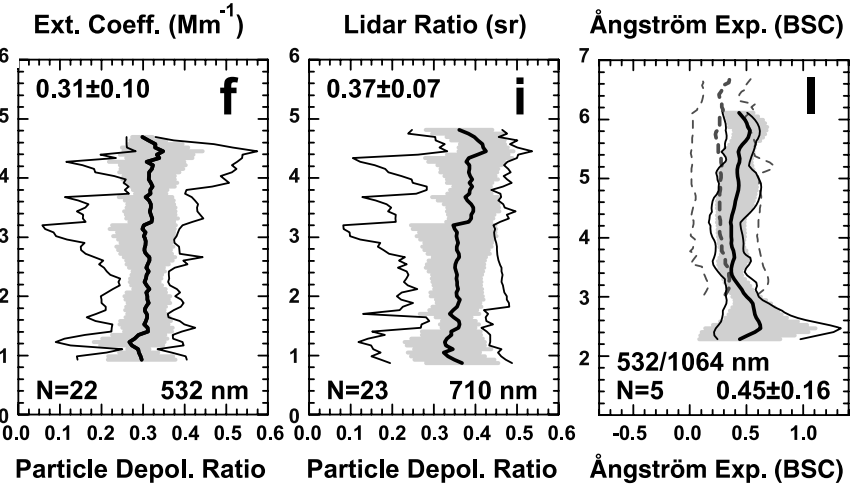

Fig. 19. Same as Fig. 12 but for observations with BERTHA during SAMUM-2b. The dashed grey profiles in (g), (h), (j), (k), and (l) represent the findings of SAMUM-1 in Morocco (see Fig. 15 in Tesche et al., 2009a).

by the column-integrated Sun photometer observations. A detailed discussion of the Sun photometer measurements during the winter campaign of SAMUM-2 is given by Toledano et al. (2011).

Finally, the range-resolved lidar observations led to spectrally resolved mean values of the lidar ratio, the Ångström exponent, and the particle depolarization ratio for the different aerosol types. The findings of all SAMUM campaigns are summarized in Table 2. For SAMUM-1, the mean values of the lidar ratios and the Ångström exponents are taken from Tesche et al. (2009a) while the particle depolarization ratios are taken from Freudenthaler et al. (2009). Note that the depolarization measurements at $710 \mathrm{~nm}$ with BERTHA in Morocco were affected with large errors. As a consequence, the setup for depolarization ratio measurements was significantly improved after SAMUM1. In Table 2, the depolarization ratios for SAMUM-2a are taken from Groß et al. (2011a) (dust, dust+smoke) and Groß et al. (2011b) (maritime). The values for pure biomass-burning smoke are taken from Tesche et al. (2011) while the remaining numbers and the findings of SAMUM-2b are presented in this paper. We are confident that the 710-nm dust depolarization ratio of $0.37 \pm 0.07$ measured during SAMUM-2 is representative for pure Saharan dust.

As presented in Figs 19g, h, j, k, and 1 no differences of intensive parameters (lidar ratio, Ångström exponent, and particle depolarization ratio) were found between the summer observations in Morocco and at Cape Verde. This suggests that no significant changes in particle microphysics occur during the first days of transport. This is in agreement with airborne observations over the Atlantic ocean during SAMUM-1. Surprisingly large particles with effective radii of 3-6 $\mu \mathrm{m}$ were observed even after transport of several thousands of kilometres 
Table 2. Overview of the findings of the SAMUM campaigns in terms of mean 500-nm AOTs, total aerosol layer top heights and depth of layers of distinct aerosol types, and extensive (backscatter and extinction coefficients) and intensive parameters (lidar ratios, Ångström exponents and particle depolarizations ratios) at various wavelengths. Values for SAMUM-1 are taken from Freudenthaler et al. (2009) (particle depolarization ratios) and Tesche et al. (2009a) (lidar ratios and Ångström exponents). SAMUM-2a values are taken from this study as well as from Groß et al. (2011a) (results for maritime aerosol and pure dust) and Tesche et al. (2011) (results for pure smoke). Note that the SAMUM-2b dust depolarization ratio at $532 \mathrm{~nm}$ was derived after conversion of the 710-nm volume depolarization ratio to $532 \mathrm{~nm}$ according to eq. (1).

\begin{tabular}{|c|c|c|c|c|c|c|}
\hline Campaign & $\begin{array}{c}\text { SAMUM-1 } \\
\text { Morocco } \\
\text { May/June } 2006\end{array}$ & \multicolumn{4}{|c|}{$\begin{array}{l}\text { SAMUM-2a } \\
\text { Cape Verde }\end{array}$} & $\begin{array}{c}\text { SAMUM-2b } \\
\text { Cape Verde } \\
\text { May/June } 2008\end{array}$ \\
\hline Mean 500-nm AOT & $0.31 \pm 0.17$ & \multicolumn{4}{|c|}{$0.35 \pm 0.18$} & $0.40 \pm 0.20$ \\
\hline Aerosol layer top height $(\mathrm{km})$ & $3.8 \pm 0.8$ & \multicolumn{4}{|c|}{$3.5 \pm 1.2$} & $4.4 \pm 0.7$ \\
\hline & \multicolumn{6}{|c|}{ Mean values between 2 and $4 \mathrm{~km}$ height asl } \\
\hline$\beta_{355}^{\mathrm{p}}\left(\mathrm{M} \mathrm{m}^{-1} \mathrm{sr}^{-1}\right)$ & $1.7 \pm 0.2$ & \multicolumn{4}{|c|}{$1.4 \pm 0.2$} & $1.4 \pm 0.2$ \\
\hline$\beta_{532}^{\mathrm{p}}\left(\mathrm{M} \mathrm{m}^{-1} \mathrm{sr}^{-1}\right)$ & $1.5 \pm 0.1$ & \multicolumn{4}{|c|}{$0.8 \pm 0.1$} & $1.4 \pm 0.1$ \\
\hline$\beta_{1064}^{\mathrm{p}}\left(\mathrm{M} \mathrm{m}^{-1} \mathrm{sr}^{-1}\right)$ & $1.4 \pm 0.1$ & \multicolumn{4}{|c|}{$0.5 \pm 0.1$} & $1.1 \pm 0.1$ \\
\hline$\alpha_{355}^{\mathrm{p}}\left(\mathrm{M} \mathrm{m}^{-1}\right)$ & $97 \pm 23$ & \multicolumn{4}{|c|}{$66 \pm 6$} & $83 \pm 6$ \\
\hline$\alpha_{532}^{\mathrm{p}}\left(\mathrm{M} \mathrm{m}^{-1}\right)$ & $97 \pm 23$ & \multicolumn{4}{|c|}{$48 \pm 5$} & $79 \pm 4$ \\
\hline & \multicolumn{6}{|c|}{ Specific findings for different aerosol types } \\
\hline Aerosol type & Dust & Maritime & Dust + smoke & Dust & Smoke & Dust \\
\hline Mean layer depth (km) & $3.8 \pm 0.8$ & $0.4 \pm 0.1$ & $3.8 \pm 0.8$ & $1.0 \pm 0.4$ & - & $4.1 \pm 0.7$ \\
\hline$S_{355}(\mathrm{sr})$ & $53 \pm 7$ & 17 & $67 \pm 14$ & 58 & $87 \pm 17$ & $53 \pm 10$ \\
\hline$S_{532}(\mathrm{sr})$ & $55 \pm 7$ & 18 & $67 \pm 12$ & 61 & $79 \pm 17$ & $54 \pm 10$ \\
\hline$S_{1064}(\mathrm{sr})$ & $55 \pm 13$ & - & - & - & - & - \\
\hline$\stackrel{\circ}{a}_{355 / 532}^{\alpha}$ & $0.06 \pm 0.21$ & - & $0.67 \pm 0.38$ & - & $1.15 \pm 0.28$ & $0.22 \pm 0.27$ \\
\hline$\stackrel{\circ}{a}_{355 / 532}^{\beta}$ & $0.19 \pm 0.20$ & - & $0.71 \pm 0.28$ & - & $0.90 \pm 0.26$ & $0.16 \pm 0.45$ \\
\hline$\stackrel{\circ}{a}_{532 / 1064}^{\beta}$ & $0.28 \pm 0.16$ & - & $0.67 \pm 0.27$ & - & $1.06 \pm 0.65$ & $0.45 \pm 0.16$ \\
\hline$\delta_{355}^{\mathrm{p}}$ & $0.26 \pm 0.06$ & 0.03 & $0.16 \pm 0.04$ & 0.25 & - & - \\
\hline$\delta_{532}^{\mathrm{p}}$ & $0.31 \pm 0.03$ & 0.03 & $0.16 \pm 0.03$ & 0.30 & $0.05 \pm 0.02$ & $0.31 \pm 0.10$ \\
\hline$\delta_{710}^{\mathrm{p}}$ & $0.28 \pm 0.05^{1}$ & - & $0.18 \pm 0.03$ & 0.36 & - & $0.37 \pm 0.07$ \\
\hline
\end{tabular}

${ }^{a}$ As mentioned in the text, we are confident that the SAMUM-2b value of $0.37 \pm 0.07$ is also representative for SAMUM-1.

(Weinzierl et al., 2009). Wandinger et al. (2010) applied the observed large effective radii from these SAMUM-1 measurements to explain the discrepancy between the dust lidar ratios of $55 \mathrm{sr}$ at $532 \mathrm{~nm}$ that were usually observed during the SAMUM campaigns (Figs 19g and h) and the value of $40 \mathrm{sr}$ used in the CALIPSO retrieval (Omar et al., 2009, 2010). They found that the presence of these large particles (which are not accounted for in the CALIPSO aerosol model for mineral dust) can explain the effects that lead to the discrepancies between the extinction profiles derived during the summer campaign of SAMUM-2 and coincident CALIPSO overflights.

\section{Summary}

We presented lidar measurements performed at Cape Verde in the framework of the second SAMUM experiment. Three groundbased and one airborne system were operated at the airport of Praia, Cape Verde, during January and February of 2008. The winter observations showed complex aerosol conditions with a Saharan dust layer in the lowermost 1-2 km and an elevated layer consisting of a mixture of biomass-burning smoke and mineral dust. The mean top height of the total aerosol layer was $3.5 \pm 1.2 \mathrm{~km}$. The mean 500-nm AOT was $0.35 \pm 0.18$. The mean total backscatter coefficients in the height range between 2 and $4 \mathrm{~km}$ were $1.4 \pm 0.2,0.8 \pm 0.1$, and $0.5 \pm 0.1 \mathrm{Mm}^{-1} \mathrm{sr}^{-1}$ at 355,532 , and $1064 \mathrm{~nm}$, respectively. The corresponding extinction coefficients were $66 \pm 6$ and $48 \pm 5 \mathrm{Mm}^{-1}$ at 355 and $532 \mathrm{~nm}$, respectively. The contribution of dust to the optical properties observed in the elevated smoke-dominated layer are estimated to vary from 40 to $60 \%$ (Tesche et al., 2009b; 2011). Lidar ratios of 60-80 sr at 355 and $532 \mathrm{~nm}$ were obtained for the aerosol mixture in the lofted layer. Considering the dust lidar ratio of 55 sr observed during SAMUM-1 (Tesche et al., 2009a) and a dust fraction of $40-60 \%$, it was concluded that the lidar ratios of pure biomass-burning smoke are in the range of $75-85$ sr. This is in agreement with Raman lidar observations 

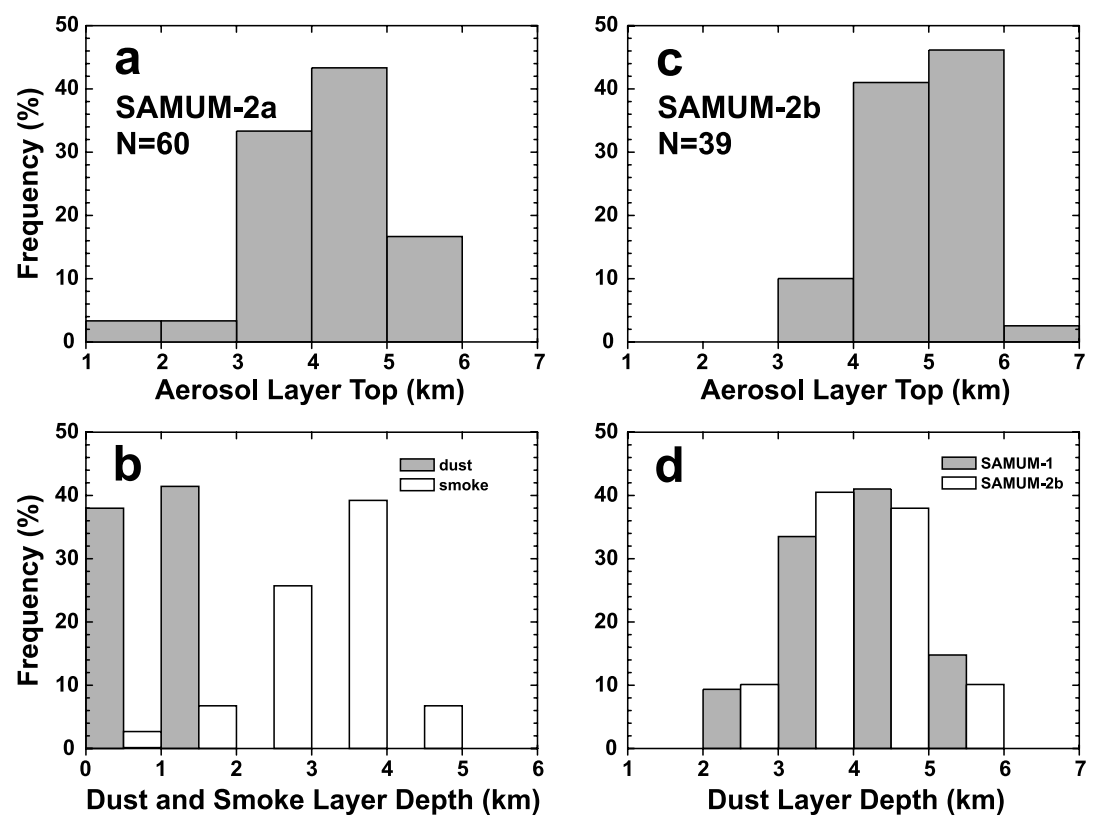

Fig. 20. Aerosol layer top heights during (a) the winter and (b) the summer campaign of SAMUM-2. Also shown are the individual depths of the dust (c, grey) and smoke-dominated (c, white) layers during the winter campaign and a comparison to the observations during summer 2008 (d, white bars) and during SAMUM-1 in Morocco (d, grey, see Tesche et al., 2009a).
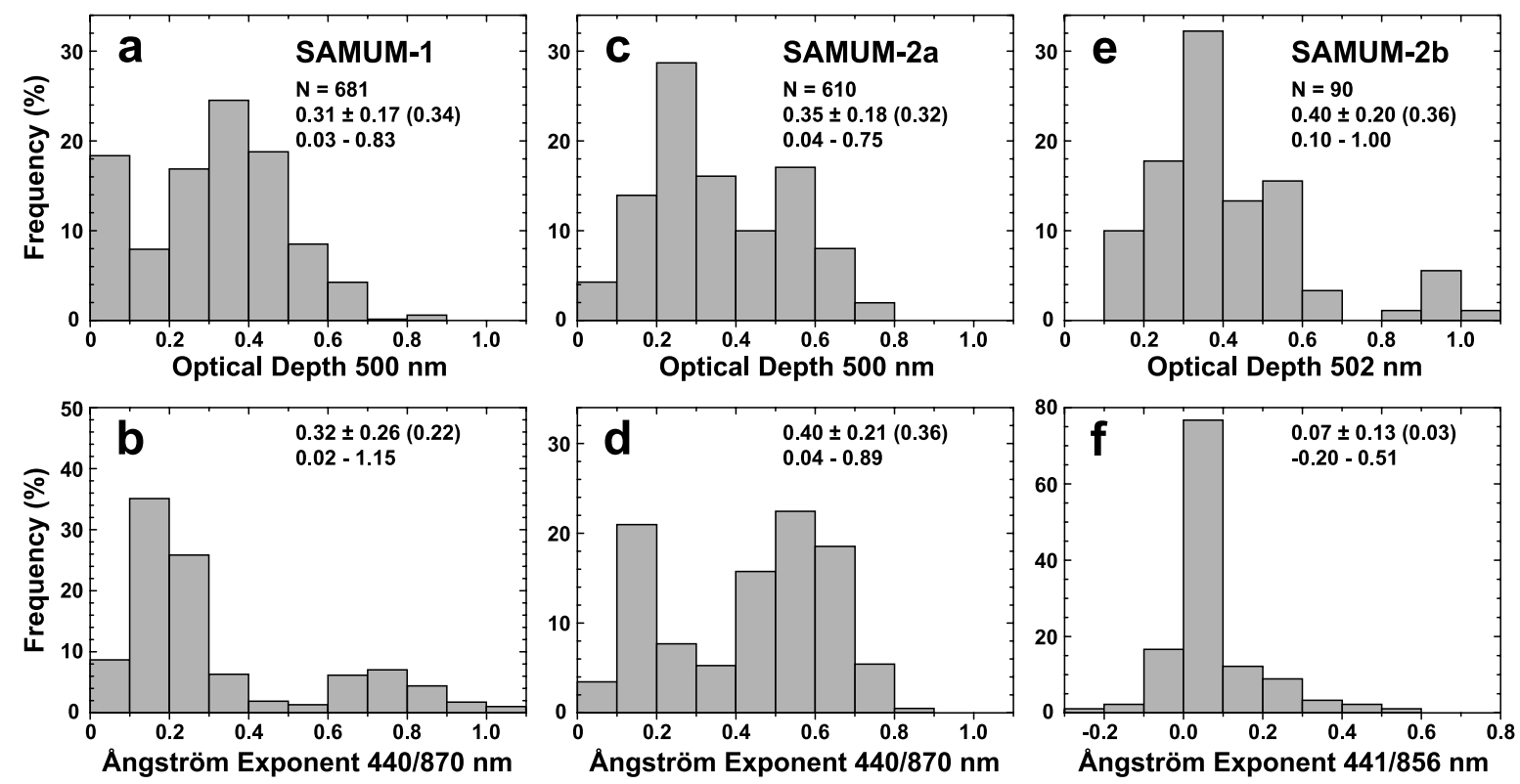

Fig. 21. Frequency distributions of the 500-nm (502-nm) optical depth and 440/870-nm (441/856-nm) Ångström exponents measured with AERONET (individual measurements) and SP1A (1-h mean values) Sun photometer during SAMUM-1 (a and b), SAMUM-2a (c and d), and SAMUM- $2 b$ (e and f). Numbers in the figure denote the mean value with standard deviation, the median (in parentheses), and the range of observed values.

during DABEX (Heese and Wiegner, 2008). Backscatter- and extinction-related Ångström exponents of the mixed dust/smoke layer all showed values around 0.7 . Particle depolarization ratios within the elevated layer showed little to no wavelength dependence (see also Groß et al., 2011a) but were much larger than values of around 0.05 at $532 \mathrm{~nm}$ that are usually observed for pure biomass-burning smoke (see discussion in Tesche et al., 2009b). Improvements of the 710-nm depolarization channels of the BERTHA receiver allowed high-quality measurements of the volume depolarization ratio during SAMUM-2.

Another four-week campaign was conducted with one lidar instrument during May and June of 2008. Pure dust conditions prevailed above a maritime boundary layer of about $1 \mathrm{~km}$ depth. The mean 500-nm AOT was $0.40 \pm 0.20$. The height of the aerosol layer top was $4.4 \pm 0.7 \mathrm{~km}$. Mean dust backscatter coefficients for the 2-4-km height range varied between 1.1 and 
$1.4 \mathrm{Mm}^{-1} \mathrm{sr}^{-1}$ at the three laser wavelength. The mean dust extinction coefficient at 355 and $532 \mathrm{~nm}$ was about $80 \pm 6 \mathrm{Mm}^{-1}$. The lidar ratios, Ångström exponents, and depolarization ratios observed within the pure dust layer during the summer campaign of SAMUM-2 show no variation from the values observed in Morocco. An important finding of SAMUM is the observed wavelength-dependence of the particle depolarization ratio with values of $0.26 \pm 0.06$ at $355 \mathrm{~nm}, 0.31 \pm 0.03$ at $532 \mathrm{~nm}$, and $0.37 \pm 0.07$ at $710 \mathrm{~nm}$.

\section{Acknowledgments}

We thank Colonel Antonio Fortes for his efforts in overcoming logistical and organizational problems of any kind. His support enabled our successful campaign in the first place. We express our deepest gratitude to the airport authority of the Republic of Cape Verde. We particularly want to thank the director of Praia airport, Euridice Mascarenhas, and her staff for the warm welcome offered to our science team. E. Mascarenhas supported us in a very extraordinary and unbureaucratic manner, which made our work at Praia airport very pleasant. We would like to acknowledge the great help we received by the airport staff members Daniel Lima and Antonio Pinheiro. We thank Brent Holben and Wayne Newcomb (deceased 18 December 2008) for providing us with the AERONET photometer and solid support. The SAMUM research group is funded by the Deutsche Forschungsgemeinschaft (DFG) under grant FOR 539. Analyses and visualizations used in this paper were produced with the Giovanni online data system, developed and maintained by the NASA GES DISC. We also acknowledge the MODIS mission scientists and associated NASA personnel for the production of the data used in this research effort.

\section{References}

Acker, J. G. and Leptoukh, G. 2007. Online analysis enhances use of NASA Earth science data. EOS 88, 14 and 17.

Althausen, D., Müller, D., Ansmann, A., Wandinger, U., Hube, H. and co-authors. 2000. Scanning 6-wavelength 11-channel aerosol lidar. $J$. Atmos. Oceanic Technol. 17, 1469-1482.

Ångström, A. 1964. The parameters of atmospheric turbidity. Tellus 16, 64-75.

Ansmann, A., Althausen, D., Wandinger, U., Franke, K., Müller, D. and co-authors. 2000. Vertical profiling of the Indian aerosol plume with six-wavelength lidar during INDOEX: A first case study. Geophys. Res. Lett. 27, 963-966.

Ansmann, A., Wandinger, U., Wiedensohler, A. and Leiterer, U. 2002. Lindenberg Aerosol Characterization Experiment 1998 (LACE 98): overview. J. Geophys. Res. 107, doi:10.1029/2000JD000233.

Ansmann, A., Bösenberg, J., Chaikovsky, A., Comerón, A., Eckhardt, S. and co-authors. 2003. Long-range transport of Saharan dust to northern Europe: The 11-16 October 2001 outbreak observed with EARLINET. J. Geophys. Res. 108, doi:10.1029/2003JD003757.
Ansmann, A. and Müller, D. 2005. Lidar and atmospheric aerosol particles. In: LIDAR-Range-Resolved Optical Remote Sensing of the Atmosphere (ed. C. Weitkamp), Springer, New York, 105-141.

Ansmann, A., Tesche, M., Althausen, D., Müller, D., Freudenthaler, V. and co-authors. 2008. Influence of Saharan dust on cloud glaciation in southern Morocco during SAMUM. J. Geophys. Res. 113, doi:10.1029/2007JD008785.

Ansmann, A., Baars, H., Tesche, M., Müller, D., Althausen, A. and co-authors. 2009a. Dust and smoke transport from Africa to South America: Lidar profiling over Cape Verde and the Amazon rain forest. Geophys. Res. Lett. 36, doi:10.1029/2009GL037923.

Ansmann, A., Tesche, M., Seifert, P., Althausen, A., Engelmann, R. and co-authors. 2009b. Evolution of the ice phase in tropical altocumulus: SAMUM lidar observations over Cape Verde. J. Geophys. Res. 114, doi:10.1029/2008JD011659.

Ansmann, A., Petzold, A., Kandler, K., Tegen, I., Wendisch, M. and coauthors. 2011. Saharan Mineral Dust Experiments SAMUM-1 and SAMUM-2: What have we learned? Tellus 63B, this issue.

Arshinov, Y., Bobrovnikov, S., Serikov, I., Ansmann, A., Wandinger, U. and co-authors. 2005. Daytime operation of a pure rotationalRaman lidar by the use of a Fabry-Perot interferometer. Appl. Opt. 44, 3593-3603.

Balis, D. S., Amiridis, V., Zerefos, C., Gerasopoulos, E., Andreae, M. and co-authors. 2003. Raman lidar and sunphotometric measurements of aerosol optical properties over Thessaloniki, Greece, during a biomass-burning episode. Atmos. Environ. 37, 4529-4538.

Balis, D. S., Amiridis, V., Nickovic, S., Papayannis, A. and Zerefos, C. 2004. Optical properties of Saharan dust layers as detected by a Raman lidar at Thessaloniki, Greece. Geophys. Res. Lett. 31, doi:10.1029/2004GL019881.

Bauer, S., Bierwirth, E., Wendisch, M., Esselborn, M., Heinold, B. and co-authors. 2011. Airborne spectral radiation measurements to estimate single-scattering albedo and radiative forcing of Saharan dust and biomass-burning smoke particles. Tellus 63B, this issue.

Ben-Ami, Y., Koren, I. and Altaratz, O. 2009. Patterns of North African dust transport over the Atlantic: Winter vs. summer, based on CALIPSO first year data. Atmos. Chem. Phys. 9, 78677875 .

Ben-Ami, Y., Koren, I., Rudich, Y., Artaxo, P., Martin, S. T. and coauthors. 2010. Transport of North African dust from the Bodélé depression to the Amazon Basin: A case study. Atmos. Chem. Phys. 10, 7533-7544.

Bucholtz, A. 1995. Rayleigh-scattering calculations for the terrestrial atmosphere. Appl. Opt. 34, 2765-2773.

Campbell, J. R., Welton, E. J., Spinhirne, J. D., Ji, Q., Tsay, S.C. and co-authors. 2003. Micropulse lidar observations of tropospheric aerosols over northeastern South Africa during the ARREX and SAFARI 2000 dry season experiments. J. Geophys. Res. 108, doi:10.1029/2002JD002563.

Cattrall, C., Reagan, J., Thome, K. and Dubovik, O. 2005. Variability of aerosol and spectral lidar and backscatter and extinction ratios of key aerosol types derived from selected Aerosol Robotic Network locations. J. Geophys. Res. 110, doi:10.1029/2004JD005124.

Draxler, R. R. and Rolph, G. D. 2010. HYSPLIT (HYbrid Single-Particle Lagrangian Integrated Trajectory) Model access via NOAA ARL READY Website (http://ready.arl.noaa.gov/HYSPLIT.php). NOAA Air Resources Laboratory, Silver Spring, MD. 
Eck, T. F., Holben, B. N., Reid, J. S., Dubovik, O., Smirnov, A. and co-authors. 1999. Wavelength dependence of the optical depth of biomass-burning, urban, and desert dust aerosols. J. Geophys. Res. 104, 31333-31349.

Eloranta, E. E. 2005. High Spectral Resolution Lidar. In: LIDARRange-resolved optical remote sensing of the atmosphere (ed. C. Weitkamp), Springer, New York, 143-164.

Engelmann, R., Ansmann, A., Tesche, M., Seifert, P., Althausen, A. and co-authors. 2011. Doppler lidar studies of heat island effects on vertical mixing of aerosols during SAMUM-2. Tellus 63B, this issue.

Esselborn, M., Wirth, M., Fix, A., Tesche, M. and Ehret, G. 2008. Airborne high spectral resolution lidar for measuring aerosol extinction and backscatter coefficients. Appl. Opt. 47, doi:10.1364/AO.47.000346.

Esselborn, M., Wirth, M., Fix, A., Weinzierl, B., Rasp, K. and co-authors. 2009. Spatial distribution and optical properties of Saharan dust observed by airborne high spectral resolution lidar during SAMUM 2006. Tellus 61B, doi:j.1600-0889.2008.00394.x.

Franke, K., Ansmann, A., Müller, D., Althausen, D., Wagner, F. and co-authors. 2001. One-year observations of particle lidar ratio over the tropical Indian ocean with Raman lidar. Geophys. Res. Lett. 28 , doi:10.1029/2001GL013671.

Franke, K., Ansmann, A., Müller, D., Althausen, D., Venkataraman, C. and co-authors. 2003. Optical properties of the Indo-Asian haze layer over the tropical Indian ocean. J. Geophys. Res. 108, doi:10.1029/2002JD002473.

Freudenthaler, V., Esselborn, M., Wiegner, M., Heese, B., Tesche, M. and co-authors. 2009. Depolarization-ratio profiling at several wavelengths in pure Saharan dust during SAMUM 2006. Tellus 61B, doi:j.1600-0889.2008.00396.x.

Gasteiger, J., Wiegner, M., Toledano, C., Gross, S., Freudenthaler, V. and co-authors. 2011. Modeling lidar-relevant optical properties of complex mineral dust aerosols. Tellus 63B, this issue.

Goudie, A. S. and Middleton, N. J. 2001. Saharan dust storms: Nature and consequences. Earth-Sci. Rev. 56, 179-204.

Groß, S., Tesche, M., Freudenthaler, V., Toledano, C., Wiegner, M. and co-authors. 2011a. Characterization of Saharan dust, marine aerosols, and a mixture of biomass-burning aerosols and dust by means of multi-wavelength depolarization- and Raman measurements during SAMUM-2. Tellus 63B, this issue.

Groß, S., Freudenthaler, V., Wiegner, M., Greiß, A., Tesche, M. and co-authors. 2011b. Characterization of the planetary boundary layer during SAMUM-2 by means of lidar measurements. Tellus $63 \mathrm{~B}$, this issue.

Haywood, J. M., Pelon, J., Formenti, P., Bharmal, N., Brooks, M. and coauthors. 2008. Overview of the Dust and Biomass-burning Experiment and African Monsoon Multidisciplinary Analysis Special Observing Period-0. J. Geophys. Res. 113, doi:10.1029/2008JD010077.

Heese, B. and Wiegner, M. 2008. Vertical aerosol profiles from Raman polarization lidar observations during the dry season AMMA field campaign. J. Geophys. Res. 113, doi:10.1029/2007JD009487.

Heese, B., Dinter, T., Esselborn, M., Müller, T., Althausen, D. and co-authors. 2009. Lidar profiles of dust optical properties over Tinfou, Morocco, during SAMUM. Tellus 61B, doi:j.16000889.2008.00404.x.

Heinold, B., Tegen, I., Bauer, S. and Wendisch, M. 2011. Regional modelling of Saharan dust and biomass burning Part 2: Direct ra- diative forcing and atmospheric dynamic response. Tellus $63 \mathrm{~B}$, this issue.

Heintzenberg, J. 2009. The SAMUM-1 experiment over southern Morocco: Overview and introduction. Tellus 61B, doi:j.16000889.2008.00403.x

Holben, B. N., Eck, T. F., Slutsker, I., Tanré, D., Buis, J. P. and co-authors. 1998. AERONET - A federated instrument network and data archive for aerosol characterization. Remote Sens. Environ. 66, 1-16.

Huang, J., Zhang, C. and Prospero, J. M. 2010. African dust outbreaks: A satellite perspective of temporal and spatial variability over the tropical Atlantic ocean. J. Geophys. Res. 115, doi:10.1029/2009JD012516.

Johnson, T. B., Osborne, S. R., Haywood, J. M. and Harrison, M. A. J. 2008a. Aircraft measurements of biomass-burning aerosol over West Africa during DABEX. J. Geophys. Res. 113, doi:10.1029/2007JD009451.

Johnson, T. B., Heese, B., McFarlane, S. A., Chazette, P., Jones, A. and co-authors. 2008b. Vertical distribution and radiative effects of mineral dust and biomass-burning aerosol over West Africa during DABEX. J. Geophys. Res. 113, doi:10.1029/2008JD009848.

Kalu, A. E. 1979. The African dust plume: Its characteristics and propagation across West Africa in winter. 95-118 in Saharan Dust (ed. C. Morales). J. Wiley and Sons, Chichester.

Kandler, K., Lieke, K., Benker, N., Küpper, M., Emmel, C. and coauthors. 2011. Ground-based off-line aerosol measurements at Praia, Cape Verde, during the Saharan Mineral Dust Experiment: Microphysical properties and mineralogy. Tellus, this issue.

Karyampudi, V. M., Palm, S. P., Reagan, J. A., Fang, H., Grant, W. B. and co-authors. 1999. Validation of the Saharan dust plume conceptual model using lidar. Bull. Am. Meteorol. Soc. 80, 1045-1075.

Kaufman, Y. J., Smirnov, A., Holben, B. N. and Dubovik, O. 2001. Baseline maritime aerosol: Methodology to derive the optical thickness and scattering properties. Geophys. Res. Lett. 28, doi:10.1029/2001GL013312.

Kaufman, Y. J., Koren, I., Remer, L. A., Tanré, D., Ginoux, P. and co-authors. 2005. Dust transport and deposition observed from the Terra-Moderate Resolution Imaging Spectroradiometer (MODIS) spacecraft over the Atlantic Ocean. J. Geophys. Res. 110, doi:10.1029/2003JD004436.

Knippertz, P., Tesche, M., Heinold, B., Kandler, K., Toledano, C. and co-authors. 2011. Dust mobilization and transport from West Africa to Cape Verde-A meteorological overview of SAMUM-2. Tellus 63B, this issue.

Léon, J.-F., Tanré, D., Pelon, J., Kaufman, Y. J., Haywood, J. M. and co-authors. 2003. Profiling of a Saharan dust outbreak based on a synergy between active and passive remote sensing. J. Geophys. Res. 108, doi:10.1029/2002JD002774.

Lieke, K., Kandler, K., Emmel, C., Petzold, A., Weinzierl, B. and coauthors. 2011. Particle chemical properties in the vertical column based on aircraft observations in the vicinity of Cape Verde islands. Tellus 63B, this issue.

Liu, Z., Omar, A., Vaughan, M., Hair, J., Kittaka, C. and co-authors. 2008a. CALIPSO lidar observations of the optical properties of Saharan dust: A case study of long-range transport. J. Geophys. Res. 113, doi:10.1029/2007JD008878.

Liu, D., Wang, Z., Liu, Z., Winker, D. and Trepte, C. 2008b. A height resolved global view of dust aerosols from the first year CALIPSO lidar measurements. J. Geophys. Res. 113, doi:10.1029/2007JD009776. 
Mattis, I., Ansmann, A., Müller, D., Wandinger, U. and Althausen, D. 2002. Dual-wavelength Raman lidar observations of the extinctionto-backscatter ratio of Saharan dust. Geophys. Res. Lett. 29, doi:10.1029/2002GL014721.

Mattis, I., Tesche, M., Grein, M., Freudenthaler, V. and Müller, D. 2009. Systematic error of lidar profiles caused by a polarization-dependent receiver transmission: Quantification and error correction scheme. Appl. Opt. 48, doi:10.1364/AO.48.002742.

Mishchenko, M. I., Travis, L. D., Kahn, R. A. and West, R. A. 1997. Modeling phase functions for dust-like tropospheric aerosols using a shape mixture of randomly oriented polydisperse spheroids. J. Geophys. Res. 102, 16831-16847.

McGill, M. J., Hlavka, D. L., Hart, W. D., Welton, E. J. and Campbell, J. R. 2003. Airborne lidar measurements of aerosol optical properties during SAFARI-2000. J. Geophys. Res. 108, doi:10.1029/2002JD002370.

Mona, L., Amodeo, A., Pandolfi, M. and Pappalardo, G. 2006. Saharan dust intrusions in the Mediterranean area: Three years of Raman lidar measurements. J. Geophys. Res. 111, doi:10.1029/2005JD006569.

Müller, D., Mattis, I., Wandinger, U., Ansmann, A., Althausen, D. and co-authors. 2003. Saharan dust over a central European EARLINETAERONET site: Combined observations with Raman lidar and Sun photometer. J. Geophys. Res. 108, doi:10.1029/2002JD002918.

Müller, D., Mattis, I., Wandinger, U., Ansmann, A., Althausen, D. and co-authors. 2005. Raman lidar observations of aged Siberian and Canadian forest fire smoke in the free troposphere over Germany in 2003: Microphysical particle characterization. J. Geophys. Res. 110, doi:10.1029/2004JD005756.

Müller, D., Ansmann, A., Mattis, I., Tesche, M., Wandinger, U. and co-authors. 2007. Aerosol-type-dependent lidar ratios observed with Raman lidar. J. Geophys. Res. 112, doi:10.1029/2006JD008292.

Müller, D., Heinold, B., Tesche, M., Tegen, I., Althausen, D. and coauthors. 2009. EARLINET observations of the 14-22-May long-range dust transport event during SAMUM 2006: Validation of results from dust transport modeling. Tellus 61B, doi:j.1600-0889.2008.00400.x.

Omar, A., Winker, D. M., Kittaka, C., Vaughan, M. A., Liu, Z. and co-authors. 2009. The CALIPSO automated aerosol classification and lidar-ratio selection algorithm. J. Atmos. Oceanic Technol. 26, 1994-2014.

Omar, A. H., Liu, Z., Vaughan, M. A., Thornhill, K. L., Kittaka, C. and co-authors. 2010. Extinction-to-backscatter ratios of Saharan dust layers derived from in-situ measurements and CALIPSO overflights during NAMMA. J. Geophys. Res. 115, doi:10.1029/ $2010 J D 014223$.

Papayannis, A., Amiridis, V., Mona, L., Tsaknakis, G., Balis, D. and co-authors. 2008. Systematic lidar observations of Saharan dust over Europe in the frame of EARLINET (2000-2002). J. Geophys. Res. 113, doi:10.1029/2007JD009028.

Pelon, J., Mallet, M., Mariscal, A., Goloub, P., Tanŕe, D. and coauthors. 2008. Microlidar observations of biomass-burning aerosol over Djougou (Benin) during African Monsoon Multidisciplinary Analysis Special Observation Period 0: Dust and Biomass-burning Experiment. J. Geophys. Res. 113, doi:10.1029/2008JD009976.

Perez, C., Nickovic, S., Baldasano, J. M., Sicard, M., Rocadenbosch, F. and co-authors. 2006. A long Saharan dust event over the western Mediterranean: Lidar, Sun photometer observations, and regional dust modeling. J. Geophys. Res. 111, doi:10.1029/2005JD006579.
Prospero, J. M. and Carlson, T. N. 1972. Vertical and areal distribution of Saharan dust over the western equatorial North Atlantic ocean. $J$. Geophys. Res. 77, 5255-5265.

Prospero, J. M. and Carlson, T. N. 1980. Saharan air outbreaks over the tropical North Atlantic. Pure Appl. Geophys. 119, 677-691.

Reid, J. S., Kinney, J. E., Westphal, D. L., Holben, B. N., Welton, E. J. and co-authors. 2003. Analysis of measurements of Saharan dust by airborne and ground-based remote sensing methods during the Puerto Rico Dust Experiment (PRIDE). J. Geophys. Res. 108, doi:10.1029/2002JD002493.

Reid, J. S., Piketh, S. J., Walker, A. L., Burger, R. P., Ross, K. E. and co-authors. 2008. An overview of $\mathrm{UAE}^{2}$ flight operations: Observations of summertime atmospheric thermodynamic and aerosol profiles of the southern Arabian Gulf. J. Geophys. Res. 113, doi:10.1029/2007JD009435.

Russel, P. B. and Heintzenberg, J. 2000. An overview of the ACE2 clear sky column closure experiment (CLEARCOLUMN). Tellus 52B, 463-483.

Sassen, K. 2005. Polarization in lidar. In: LIDAR-Range-Resolved Optical Remote Sensing of the Atmosphere (eds C. Weitkamp), Springer, New York, 105-141.

Schepanski, K., Tegen, I. and Macke, A. 2009. Saharan dust transport and deposition towards the tropical northern Atlantic. Atmos. Chem. Phys. 9, 1173-1189.

Sokolik, I., Winker, D. M., Bergametti, G., Kaufmann, Y. J., Gomes, L. and co-authors. 2001. Introduction to special section: Outstanding problems in quantifying the radiative impacts of mineral dust. $J$. Geophys. Res. 106, doi:10.1029/2000JD900498.

Tanré, D., Haywood, J., Pelon, J., Léon, J.-F., Chatenet, B. and coauthors. 2003. Measurements and modeling of the Saharan dust radiative impact: overview of the Saharan Dust Experiment (SHADE). J. Geophys. Res. 108, doi:10.1029/2002JD003273.

Tesche, M., Ansmann, A., Müller, D., Althausen, D., Mattis, I. and coauthors. 2009a. Vertical profiling of Saharan dust with Raman lidars and airborne HSRL in southern Morocco during SAMUM. Tellus 61B, doi:j.1600-0889.2008.00390.x.

Tesche, M., Ansmann, A., Müller, D., Althausen, D., Engelmann, R. and co-authors. 2009b. Vertically resolved separation of dust and smoke over Cape Verde by using multiwavelength Raman and polarization lidars during Saharan Mineral Dust Experiment 2008. J. Geophys. Res. 114, doi:10.1029/2009JD011862.

Tesche, M., Müller, D., Groß, S., Ansmann, A., Althausen, D. and coauthors. 2011. Optical and microphysical properties of smoke over Cape Verde inferred from multiwavelength lidar measurements. Tellus 63B, this issue.

Toledano, C., Wiegner, M., Garhammer, M., Seefeldner, M., Gasteiger, J. and co-authors. 2009. Spectral aerosol optical depth characterization of desert dust during SAMUM 2006. Tellus 61B, 10.1111/j.16000889.2008.00382.x.

Toledano, C., Wiegner, M., Garhammer, M., Seefeldner, M., Garsteiger, J. and co-authors. 2011. Optical properties of aerosol mixtures derived from sun-sky radiometry during SAMUM-2. Tellus 63B, this issue.

Wandinger, U. and Ansmann, A. 2002. Experimental determination of the lidar overlap profile with Raman lidar. Appl. Opt. 41, 511514.

Wandinger, U., Müller, D., Böckmann, C., Althausen, D., Matthias, V., and co-authors. 2002. Optical and microphysical characterization 
of biomass-burning and industrial-pollution aerosols from multiwavelength lidar and aircraft measurements. J. Geophys. Res. 107, doi:10.1029/2000JD000202.

Wandinger, U., Tesche, M., Seifert, P., Ansmann, A., Müller, D. and co-authors. 2010. Size matters: Influence of multiple scattering on CALIPSO light-extinction profiling in desert dust. Geophys. Res. Lett. 37, doi:10.1029/2010GL042527.

Weinzierl, B., Petzold, A., Esselborn, M., Wirth, M., Rasp, K. and coauthors. 2009. Airborne measurements of dust layer properties, parti- cle size distribution and mixing state of Saharan dust during SAMUM 2006. Tellus 61B, doi:j.1600-0889.2008.00392.x.

Weinzierl, B., Sauer, D., Esselborn, M., Petzold, A., Mund, S. and coauthors. 2011. Airborne observations of microphysical and optical properties of dust and biomass-burning aerosol layers in the Cape Verde region during SAMUM 2008. Tellus 63B, this issue.

Winker, D. M., Vaughan, M. A., Omar, A., Hu, Y., Powell, K. A. and coauthors. 2009. Overview of the CALIPSO mission and CALIOP data processing algorithms. J. Atmos. Oceanic Technol. 26, 2310-2323. 